\title{
La participación de los senadores de origen africano en los sacerdocios públicos de Roma
}

\author{
The participation of the senators from African origin \\ in the public priesthoods of Rome
}

\author{
Isabel Salcedo de PRAdo*
}

\begin{abstract}
RESUMEN
El análisis del cursus honorum de un senador permite comprobar el grado de promoción de éste entre la elite política del Imperio. Desde otra perspectiva, el estudio de su participación en los sacerdocios públicos de Roma permite comprobar su nivel de integración entre las familias y grupos sociales más prestigiosos de la Urbs. Por ello resulta muy interesante abordar el análisis de la participación en estos sacerdocios de un grupo provincial emergente en el siglo segundo, el de los senadores de origen africano. De esta forma se dibujará con mayor precisión la integración africana en el conjunto socio-político y mental romano.

Se señalarán los principales personajes en este sentido, comprobándose de esta forma si la integración africana entre estos sacerdocios fue paralela a su promoción política.

PALABRAS CLAVE

Senadores africanos, sacerdocios públicos romanos, promoción, quattuor amplissima collegia, sacerdotia minora.
\end{abstract}

\begin{abstract}
The analysis of the cursus honorum of a senator reveals his level of promotion amidst the political elite of the Empire. From another perspective, the study of his participation in Roman public priesthood enables to ascertain his level of integration in families and within the most prestigious social groups of the Urbs. It is, therefore, extremely interesting to analyse the participation in these priesthoods of an emerging provincial group in the second century, namely the senators of African origin. This will provide a more accurate picture of African integration in the Roman socio-political and mental ensemble. The main protagonists in this respect will be mentioned in order to determine whether African integration among these priesthoods was parallel to their political promotion.

\section{KEYWORDS}

African senators, Roman public priesthood, promotion, quattuor amplissima collegia, sacerdotia minora.
\end{abstract}

Recibido el 1 de junio de 2012. Aceptado el 25 de julio de 2012

** Miembro del grupo de investigación ORDO IV: «Topografia funcional de las elites: la expresión de la influencia y el poder de las elites en la pars occidentalis del Imperio Romano»; dentro del subproyec- 
Tradicionalmente se ha considerado el análisis del cursus honorum senatorial como modelo paradigmático para comprobar la promoción de un personaje entre la elite política del Imperio. Sin embargo, otro factor que puede resultar ciertamente revelador es el estudio de su participación en los sacerdocios públicos de Roma, pues ilustra, desde otra perspectiva, el nivel de integración entre las familias y grupos sociales más prestigiosos de la Urbs. Por ello se plantea particularmente interesante comprobar la participación en estos sacerdocios de un grupo provincial emergente en el siglo segundo, el de los senadores de origen africano ${ }^{1}$, quienes a finales de dicha centuria alcanzarían altísimas cotas de poder. Basta recordar cómo en el 193 Septimio Severo inauguró un gobierno que alzaba a un africano, de orígenes púnicos, como el principal, el primero, el Imperator del pueblo romano.

El estudio de la incorporación de este contingente social a la religión de la Urbs resulta verdaderamente ilustrativo por demostrar ser todo un símbolo de la adecuación e identificación progresiva de las gentes africanas con los habitantes de Roma. Esta homogeneización alcanzaba un mayor significando cuando se trataba de ocupar los puestos más altos y de mayor prestigio dentro de la estratificada organización religiosa. Estos puestos estaban destinados al ordo senatorial, pero incluso entre ellos se distinguían aquellos considerados como los sacerdocios más prestigiosos, los quattuor amplissima collegia, esto es, el colegio de los pontifices, augures, XVviri sacris faciundis y VIIviri Epulonum. Esta estratificación lógica alimentaba, y por otro lado saciaba las aspiraciones de la clase dirigente, que así como se observaba en el terreno propio del cursus honorum, estaba ávida de distinción y prestigio. Gustaba y necesitaba distinguirse, y en el desempeño de los sacerdocios públicos encontraba una nueva «marca de status»².

Por tanto resulta preciso analizar la promoción africana entre esta élite religiosa, pues es otra dimensión desde la que se puede dibujar con mayor precisión la

to «La implicación imperial de las elites oriundas de las provincias hispanas y norteafricanas» (Universidad de Sevilla). Miembro asimismo del grupo de investigación «La Bética romana: su patrimonio histórico» (HUM -323) del Plan Andaluz de Investigación de la Junta de Andalucía. Universidad de Sevilla, Facultad de Geografía e Historia, Departamento de Historia Antigua. C/ Doña María de Padilla s/n, Sevilla 41004. Mail: isalcedo@us.es

1 El estudio de los senadores romanos de origen africano ha sido abordado en SALCEDO DE PRADO, Isabel, Senadores romanos de origen africano, (Tesis doctoral s.p.), Universidad de Navarra, 2011. En ella se ha llevado a cabo un minucioso análisis tanto de la promoción social, cultural y familiar de los senadores de origen africano, como de sus carreras públicas y la integración africana en el ordo senatorius.

2 En este sentido es muy interesante el artículo de SAQUETE, Jose Carlos, «La integración de las elites hispanas en Roma. El caso de la religión pública y los senadores béticos», en CABALLOS RUFINO, Antonio, DEMOUGIN, Ségolène (eds.) Migrare : la formation des élites dans l'Hispanie romaine, Burdeos-París, de Boccard, 2006, pp. 301-337. En este estudio destinado al análisis de los senadores béticos, utiliza precisamente el caso de la religión pública romana como valor para observar el nivel de integración de estos clarísimos. Saquete defiende que, al margen del estudio de la participación en las magistraturas, la integración de un grupo social se manifiesta también en otros aspectos. Así propone como hipótesis de trabajo el estudio de los sacerdocios públicos romanos entre la elite senatorial bética, como valor indicativo de la importancia de cada senador, de sus posibilidades de promoción y de su nivel de cercanía a la figura imperial. 
integración africana en el conjunto socio-político y mental romano. De igual modo es fundamental descubrir los canales temporales de esta promoción, así como señalar los personajes más ilustres en este sentido, comprobándose si la promoción política se plasmó de manera paralela o no dentro del cuadro organizativo de la religión pública romana.

Cabe aclarar en primer lugar los límites geográficos y cronológicos que enmarcan este estudio. Geográficamente el trabajo ha considerado a la elite senatorial procedente de las provincias septentrionales de África ${ }^{3}$. Tradicionalmente los estudios referidos al Norte africano han concebido así el marco geográfico, incluyendo por tanto las cuatro provincias romanas: la Mauretania Caesarensis, la Mauretania Tingitana, Numidia y el Africa Proconsularis. Sin embargo no fue un territorio homogéneo, y ni siquiera la romanidad se expresó de igual modo en toda esta zona, como se apreciará concretamente en la participación de los senadores oriundos de una u otra provincia en los sacerdocios públicos romanos.

En cuanto a los parámetros cronológicos que han limitado el estudio lógicamente se ha considerado como fecha de inicio la propia incorporación de los africanos al Senado, esto es, en época Flavia. Se ha establecido el límite superior en el año 260, momento en el que Galieno asumió el poder imperial de manera individual, y comenzó a acometer reformas fundamentales, que tendrían su afectación radical en el grupo senatorial ${ }^{4}$

\section{LOS SACERDOCIOS PÚBLICOS ROMANOS}

La religión romana había formado parte del imaginario romano desde sus más tempranos orígenes. Progresivamente se irían creando los diversos sacerdocios públicos encargados de su culto, y así como sucedió con las magistraturas, éstos se fueron conformando como parte intrínseca del cursus honorum ${ }^{5}$. Pero al igual que ocurriría paralelamente con las magistraturas, el cambio al nuevo régimen imperial imprimiría un carácter totalmente nuevo a los sacerdocios públicos ${ }^{6}$. Éstos fueron desprovistos de su poder fáctico pero se convirtieron en un nuevo elemento de distinción y honra. Su fundamento, entre otras cosas, se basaba en que

3 Hasta la Cirenaica, por pertenecer ésta al mundo helénico y tener un carácter distinto.

4 Para entender las reformas de Galieno en relación con el cursus honorum senatorial son fundamentales los estudios de CHRISTOL, Michel «Les réformes de Gallien et la carrière sénatoriale», Epigrafía e ordine Senatorio, Tituli 4, Roma, Ed. di Storia \& Letter, 1982, pp. 143-166; Ídem, Essai sur l'évolution des carrières sénatoriales dans la $2^{a}$ moité du III siècle ap. J.C., París, Nouvelles Éd. latines, 1986.

5 SZEMLER, G. J. (1986) «Priesthoods and Priestly Careers in Ancient Rome», Aufstieg und Niedergang der römischen Welt, II, 16.3, Berlín-Nueva York, de Gruyter, 1986, pp. 2314-2331.

6 En cuanto a las reformas llevadas a cabo por Augusto, cfr. entre otros SYME, Ronald, The Augustan Aristocracy, Oxford, Clarendon Press, 1985, pág. 4; SCHEID, John, «Auguste et le grand pontificat. Politique et droit sacré au début du Principat», RHDFE, 77, (1999), pp. 1ss.; Ídem, «Honorer le prince et vénérer les dieux: culte public, culte des quartiers et culte imperial dan la Rome augustéenne», en BELAYCHE, Nicole. (ed.), Rome, les Césars et la Ville aux deux premiers siècles de notre ère, Rennes, Presses Universitaires de Rennes, 2001, pp. 85ss. 
para formar parte de un colegio sacerdotal era necesaria la aprobación del emperador $^{7}$, aunque se mantuvieran las apariencias de una elección por parte de los propios miembros del colegio (cooptatio). Si en última instancia era el favor imperial el que determinaba la pertenencia a uno de los collegia, la obtención de un sacerdocio público pasaba a significar una necesaria predilección por parte de la figura imperial. No sólo era necesaria la aprobación del emperador, sino que formar parte de la plantilla de uno de los collegia más importantes suponía, a su vez, una necesaria cercanía a su persona, pues el emperador era miembro de los cuatro colegios principales, así como de los fratres Arvales, sodales Titii y fetiales.

En definitiva, el ejercicio de un sacerdocio público, máxime si éste era uno de los principales, suponía la obtención del favor imperial, podía abrir las puertas de una próxima promoción y sobre todo suponía una marca de distinción frente a otros, quizá políticamente iguales.

Como se ha mencionado existía cierta jerarquización interna dentro del complejo de sacerdocios públicos, de tal forma que otorgaba mayor dignidad formar parte de alguno de los sacerdocios de los amplissima collegia ${ }^{8}$. Dentro de éstos el más prestigioso era el colegio de los pontifices, seguido del de augures, XVviri sacris faciundis, y en último lugar el de los VIIviri Epulonum. Paralelamente, se documenta un mayor número de patricios entre los dos primeros, mientras que entre los XVviri y VIIviri son mayoría los plebeyos ${ }^{9}$.

Pero, si formar parte de alguno de los sacerdocios de los amplissima collegia confería un mayor prestigio, de manera correlativa también era más difícil ser cooptado para formar parte de ellos. Además los elegidos recibían el puesto de por vida, cuestión que si cabe dificultaba más la entrada de nuevos aspirantes. A su vez algunos de los senadores más influyentes podían pertenecer a más de un colegio sacerdotal, aunque sólo en raras ocasiones se permitía la acumulación de dos sacerdocios mayores. Sin embargo era posible formar parte de uno de los mayores y de otro, o varios, de los sacerdotia minora, esto es ser fetialis, frater Arvalis, Salius, sodalis Titius o pertenecer a algunas de las sodalitates imperiales ${ }^{10}$.

7 S CHUMACHER, Leonhard, «Staatsdienst und Kooptation. Zur sozialen Struktur römischer Priesterkollegien im Prinzipat», Epigrafia e ordine senatorio, Tituli 4, Roma, Ed. di Storia \& Letter, Roma, 1982, pp. 252ss.

8 Sobre los cuatro principales sacerdocios cfr. SCHEID, John, (1978) «Les prêtres officiels sous les empereurs julio-claudiens», Aufstieg und Niedergang der römischen Welt II, 16.1, Berlín-Nueva York, de Gruyter, pp. 610-654; SCHUMACHER, Leonhard, (1978) «Die vier hohen römischen Priesterkollegien unter den Flaviern, den Antoninen und den Severern (69-235 n.Chr.) », Aufstieg und Niedergang der römischen Welt, II, 16,1, Berlín-Nueva York, de Gruyter, pp. 655-819.

9 Ídem, pp. 783-786.

10 Comenzaron a la muerte de Augusto, con su divinización. Los primeros por tanto fueron los sodales Augustales, y más tarde se crearían los Flaviales Titiales, Hadrianales y Antoniniani. Sobre estos sacerdocios cfr. PFLAUM, Hans-Georg, Les sodales Antoniniani de l'epoque de Marc Aurèle, París, Klincksieck, 1966; Ídem, "Les prêtres du culte impérial sous le règne d'Antonine le Pieux», CRAI, (1967), pp. 194s; RÜPKE, Jörg (2005) Fasti Sacerdotum: die Mitglieder der Priesterschaften und das sakrale Funktionspersonal römischer, griechischer, orientalischer und jüdisch-christlicher Kulte in der Stadt Rom von 300 v. Chr. bis 499 n. Chr., Stuttgart, Steiner, 2005, pp. 23-24. 
Todo esto dificultaba las aspiraciones de muchos senadores de formar parte de un colegio sacerdotal, habida cuenta de la tendencia entre algunas familias a heredar el puesto ${ }^{11}$.

A tenor de estas dificultades y comprendido el valor de formar parte de uno u otro colegio, se puede analizar el caso africano atendiendo como parámetro valorativo al grado de integración en los amplissima collegia, al índice de participación general en estos sacerdocios públicos, así como a su representatividad a lo largo del periodo estudiado. Así se entenderá el interés y las posibilidades de los africanos para integrarse en el imaginario religioso de la Urbs.

\section{LOS SENADORES AFRICANOS Y LOS SACERDOCIOS PÚBLICOS ROMANOS}

Están documentados un total de cuarenta y nueve africanos que fueron honrados con uno o más sacerdocios a lo largo de su carrera. Si se compara por ejemplo con el número de cónsules africanos, alrededor de la centena ${ }^{12}$, se podría establecer que la proporción de sacerdocios conocidos es, en términos cuantitativos, la mitad. Esta diferencia, siendo la cifra de sacerdocios más parecida a la de las magistraturas primeras del cursus, no radicaría en la falta de fuentes, pues en este caso este elemento del cursus se vería afectado como el resto de magistraturas, o si cabe en menor proporción que los primeros puestos de la carrera ${ }^{13}$. Sin embargo podría indicar que realmente los africanos no accedieron a esta «marca de status» ${ }^{14}$ con la misma fluidez que, volviendo a la comparación, al consulado. Una vez constatado este dato, se trata de comprobar por qué no fueron tantos los que pertenecieron a esta elite religiosa, y para eso es fundamental analizar quienes sí formaron parte de ella.

\subsection{Los quattuor amplissima collegia}

Entre los sacerdotes de origen africano veinte ${ }^{15}$ conseguirían acceder a alguno de los quattuor amplissima collegia sacerdotia. De entre ellos el principal y primer

11 Sobre la herencia entre los sacerdocios del amplissima collegia, cfr. SCHUMACHER, L., Die vier hohen römischen Priesterkollegien..., pp. 773-777; SCHEID, John, Les Frères Arvales: recrutement et origine sociale sous les empereurs Julio-Claudiens, París, Presses Universitaires, 1975, p. 329; Ídem, Les prêtres officiels..., p. 635; Ídem, Le collège des frères arvales. Etude prosopographique du recrutement (69-304), Roma, L'Erma di Bretschneider, 1990, pp. 170-171.

12 SALCEDO DE PRADO, I., Op. Cit. p. 245.

13 Cabe recordar que es muy frecuente que epigráficamente los sacerdocios estén enunciados al principio, junto al ejercicio del consulado, al margen del lugar cronológico que hubieran ocupado en el desarrollo del cursus.

14 SAQUETE, J.C., Op. Cit., p. 302.

15 Aunque L. Annius Fabianus, salius Palatinus en el 189 pudo haber sido flamen cooptado en alguno de los colegios mayores, cfr. Apéndice documental: no-25. 
colegio era el de los pontifices, que según cuenta la tradición fue fundado por Numa Pompilius ${ }^{16}$. Al colegio le competía la supervisión general de la religión de la ciudad, con el fin de velar por la pax deorum, mantenerla y vigilar que ninguna acción pudiera romperla. Por ello su actividad originariamente tenía una gran influencia sobre las leyes civiles, además los pontífices tenían autoridad sobre los demás sacerdocios y eran los principales encargados de organizar los actos de culto. En un principio este colegio estuvo reservado a los patricios, pero a lo largo de la República la participación fue ampliada progresivamente a los plebeyos, aunque siempre quedó en manos de la elite.

La composición de este collegium era ciertamente compleja pues estaba integrado por los propios pontifices dirigidos por el pontifex maximus, el rex sacrorum y los tres flamines maiores ${ }^{17}$, y los pontifices minores ${ }^{18}$. El cambio al nuevo sistema imperial tuvo una fuerte impronta sobre el colegio, pues desde César el cargo de pontifex maximus fue monopolio del princeps, y la elección de los miembros del collegium dependía directamente del favor del emperador. A su vez los que pudieron acceder a tal honor gozaban de la posibilidad de un permanente contacto con el emperador, lo que facilitaba todavía más las posibilidades de promoción.

Entre los africanos únicamente dos están documentados como miembros de este colegio, ambos pontifices. No es de extrañar que los dos africanos que lo consiguieron fueran Salvius Iulianus ${ }^{19}$, y Fulvius Plautianus ${ }^{20}$, sin duda ambos personajes de gran relieve e influencia, y de íntima proximidad con la figura imperial. Desde Adriano a Marco Aurelio el famoso jurista lulianus ${ }^{21}$ gustó de la

16 Liv. I, 20,5-7.

17 La figura del rex sacrorum procedía de los comienzos de la república, cuando tras la expulsión del último monarca, éste asumió sus sagradas obligaciones. Originariamente estaban apartados de la vida política, ya que no podían desarrollar ninguna magistratura, y aunque al principio no debió de ser así, estaban subordinados al pontífice máximo. El origen de los tres flamines maiores también era antiguo, y se les atribuían los antiguos cultos a Júpiter (flamen Dialis), Marte (flamen Martialis) y Quirino (flamen Quirinalis). Eran elegidos, de por vida, directamente por el pontifex maximus y debían proceder de familias patricias.(RÜPKE, J., Op. Cit., pp. 19-20)

18 Relacionados con el colegio, aunque no propiamente miembros de éste, estarían las Vestales y los doce flamines minores.

19 Apéndice documental: nำ10.

20 Apéndice documental: $\mathrm{n}$ 응.

21 Afamado jurista originario de Hadrumetum ( HA. vit. Did. Iul , 1, 2; PIR ${ }^{2}$ S 136; PELLETIER, André «Les Sénateurs d'Afrique proconsulaire d'Auguste à Gallien», Latomus, 23, (1964), p. 517, no 76; CORBIER, Mireille «Les familles clarissimes d'Afrique Proconsulaire (ler-Ille siecle)», Epigrafía e ordine Senatorio, Tituli 5, Roma, Ed. di Storia \& Letter, 1982, pp. 719-720) Su éxito se entiende por el prestigio del que gozó en relación con sus conocimientos jurídicos, lo que le hizo contar con la confianza de todos los emperadores de su tiempo. Adriano fue el primero que depositó en él su confianza y al tiempo que desarrollaba la cuestura junto a él le encomendó la edición del Edicto Perpetuo ( CIL VIII, 24094 = ILPBardo 417 = D 8973 = ILTun 797 = AE 1956, 124) Además, este afamado jurista, no sólo consiguió trazar una brillante carrera jalonada por el consulado ordinario en el 148, los gobierno en Germania Inferior (150?152? d.C.) e Hispania Citerior 164-167?d.C.), y el proconsulado de África (167-168 d.C.), sino que paralelamente se adentró en el ámbito de mayor confianza del emperador, formando parte permanente del consilium principis y siendo considerado entre sus amici ( HA vit. Hadr . 18, 1; CROOK, John Anthony, Consilium principis, imperial councils and counsellors from Augustus to Diocletiann, Cambridge, University Press, 1955, p. 182, n²92) Bajo Antonino Pío mantuvo su influencia, al tiempo que Marco Aurelio y Lucio Vero lo consideraron entre sus más próximos. 
amistad imperial, por lo que no sería difícil que consiguiera el favor del emperador para formar parte de este ilustre colegio. La amicitia con la familia imperial justificaría a su vez que lulianus formara parte de las sodalitates imperiales que dieron culto a sus grandes patrocinadores, siendo sodalis Hadrianalis y Antoninianus ${ }^{22}$.

El caso de Plautianus ${ }^{23}$ es todavía más significativo, pues es uno de los pocos casos en los que se concentra en la misma persona dos sacerdocios mayores $^{24}$. Conocida es la proyección de Plautianus, quien desde la prefectura del pretorio fue promocionado política y socialmente a mediados del gobierno del emperador africano. Plautianus accedería al más prestigioso sacerdocio, al pontificado, probablemente en el 202, y al año siguiente al colegio de los XVviri, poco antes de caer en desgracia. Justo en su persona hay una simbiosis entre éxito político y social, pues al mismo tiempo que obtenía dichos sacerdocios era elevado al patriciado, se unía familiarmente al emperador y era aupado a un segundo consulado ordinario.

Tanto Iulianus como Plautianus fueron actores principales de la política de su tiempo, y cosecharon sin duda grandes éxitos profesionales, entre otros ser considerados como miembros de este colegio, pero ambos lo debieron todo a sus méritos personales y a la capacidad que tuvieron para procurarse la protección imperial. Pero, lo que es realmente destacable es que entre los africanos ningún miembro de familias ya consolidadas alcanzara este honor, sino que fueran precisamente dos hombres nuevos en la Curia los que lo consiguieron.

El resto de africanos documentados se distribuyen prácticamente de forma paralela entre los demás sacerdocios mayores, siendo cinco los augures ${ }^{25}$, ocho

22 Creadas en el 161 a la muerte de Antonino Pío.

${ }^{23}$ Quizá fue praefectus vehiculorum y procurator XX hereditatium (IRT 572), y ciertamente praefectus vigilum y praefectus praetorio desde el 197. Plautianus fue progresivamente aumentando su poder, recibiendo los ornamenta consularia (197-202 d.C.) y concertando el matrimonio de su hija Plautilla con Caracalla. Sería adlectus inter patricias familias y cónsul ordinario en el 203 junto al hermano de Severo, Geta. Pero entonces comenzó su declive personal, pues el matrimonio de su hija fracasó, las relaciones con Caracalla fueron funestas al igual que con la mujer de Severo, Julia Domna, y con Geta. Fue denunciado como enemigo público, y finalmente asesinado en el palacio imperial en el 205, sufriendo la damnatio memoriae. Cfr. PIR ${ }^{2}$ F 554; PFLAUM, Hans-Georg, Les carrières procuratoriennes équestres sous le Haut-Empire romain, París, Geuthner, 1960-1982), no 271; JARRETT, Michael G., «An Album of the Equestrians from North Africa in the Emperor's Service», Epigraphische Studien 9, Bonn, p. 180, nํ 62; CORBIER, M., Les familles clarissimes d'Afrique...p. 722; LEUNISSEN, Paul M.M., Konsuln und konsulare in der Zeit von Commodus bis Severus Alexander: (180-235 n. Chr.): Prosopographische Untersuchungen zur senatorischen Elite im römischen Kaiserreich, Amsterdam, Gieben, 1989, p. 134; SABLAYROLLES, Robert, Les cohortes de vigiles, Roma, Ecole Française de Rome, 1996, pp. 377-378; CHRISTOL, Michel, «L'épigraphie de Thugga et la carrière de Plautian», en Khanoussı, M., MAuRIN, L. (eds.) Dougga (Thugga): études épigraphiques (Table Ronde, Bordeaux, 24-25 mai 1996), París, De Boccard, 1997, pp. 127-140.

24 SCHUMACHER, L., Die vier hohen römischen Priesterkollegien....p. 675, no 97.

25 Apéndice documental: C. Arrius Antoninus (n12), C. Arrius Calpurnius Frontinus Honoratus (n-41), M. Aurelius Cominius Cassianus (n-44), C. Arrius Calpurnius Longinus (n46), C. Memmius Caecilianus Placidus ( $\mathrm{n}-48$ ) 
los XVviri26 y seis los VIIviri27. Los augures ocupaban un segundo lugar dentro de los amplissima collegia, y eran los encargados de interpretar la voluntad de los dioses mediante señales divinas, normalmente relacionadas con el vuelo de las aves, y de darla a conocer (nuntatio). Su origen se remonta al primer augur, Rómulo, aunque Numa reorganizó el conjunto sacerdotal ${ }^{28}$. Sus miembros eran cooptados, elegidos dentro del colegio, y su número fue incrementándose hasta dieciséis con César ${ }^{29}$; si bien, durante el Imperio el número podía aumentar pues el princeps se guardaba el derecho de nominar supra numerum, con lo que favorecía sobre todo a miembros de la familia imperial.

El tercer puesto dentro de los amplissima collegia era ocupado por los XVviri sacris faciundis, que eran los responsables de interpretar los proféticos libros Sibilinos (libri Sibyllini), y en dignidad sucedían a los pontifices y augures. Los septemviri Epulonum eran los miembros del cuarto colegio ${ }^{30}$, y en prestigio también los últimos. Fue además el último colegio creado (s. Il a.C.) y hasta Augusto, que perteneció él mismo a este colegio, no pasó a formar parte de los amplissima collegia $^{31}$. Fueron creados para aliviar las tareas del colegio pontificio ${ }^{32}$, y entre sus competencias estaba la de organizar unos banquetes en los que se realizaban sacrificios (lovis epulum) a Júpiter, Juno y Minerva originariamente durante los ludi plebeii, y en adelante en los ludi Romani.

Entre los africanos se observa también cierta jerarquización interna dentro de

26 Apéndice documental: C. Septimius Severus (n7), Q. Aiacius Modestus Crescentianus (nำ3), L. Cornelius Salvius Tuscus ( $\mathrm{n} \times 24)$, L. Pullaienus Gargilius Antiquus ( $\mathrm{n}$-26), Iulius Pompeius Rusonianus

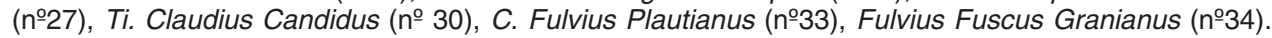
Además hay un anónimo documentado en Thugga (AE 1963, 94), defensor de la pértiga Cartaginense, que sería XVvir s. $f$. Según Schumacher no debía de ser natural de allí, porque no se conocen XVviri africanos para esa época, cfr. SCHUMACHER, L., Die vier hohen römischen Priesterkollegien..., pp. 684, n29. Tampoco serían propiamente africanos M. Cocceius Anicius Faustus Flavianus, XVvir s.f., patrono y curator de Cirta; ni L. Mummius Faustinianus, XVvir s.f. quien mantenía estrechos lazos con Thugga. Muy hipotética es también la procedencia de M. Fabius Magnus Valerianus, XVvir y Lupercus. No se ha considerado tampoco a [-] ]anus de Sufetula (CIL VIII 11338=D 1198), pues debió de ejercer los sacerdocios después de Galieno: XVvir s.f., XIlvir urbis Romae (RÜPKE, J., Op. Cit., p. 705, no 294) De igual forma otro anónimo de Sufetula ( AE 1949, 61= AE 1957, 325) sería XVvir s.f. pero, aunque RÜPKE, J., Op. Cit., pp. 667-668, no 43 siguiendo a LEUNISSEN, P.M.M., Op. Cit., p. 172s, lo sitúa en época severiana, parece más probable, según CHRISTOL, M., Essai sur l'évolution...,pp. 306-311 datarlo en una cronología más tardía, en época de Galieno. Así también lo cree FITZ, Jenö, Die Verwaltung Pannoniens in der Romerzeit, III, Budapest, Encyclopedia, 1994, nº68, pp. 1024-1025, tal y como habían propuesto previamente PFLAUM, Hans-Georg y PICARD, Guilbert. «Une carrière sénatoriale au temps de l'anarchie militaire», Karthago, 2, (1951), pp. 100-104.

27 Apéndice documental: Pactumeius Rufus ( $\mathrm{n}-2)$, M. Valerius Quadratus ( $\mathrm{n} \div 5$ ), M. Postumius Festus (n9), Sex. Caecilius Aemilianus (n22), Ti. Claudius Claudianus (n28), P. Aelius Secundinus (nำ42).

${ }^{28}$ Liv. IV, 4, 2.

29 Cass. Dio XLII, 51.

30 R. Gest. div. Aug. IX, 1; Cass. Dio LIII, 1, 5.

31 R. Gest. div. Aug. VII

32 Creados para ayudar a los pontífices, estaban sujetos a su autoridad. Cass. Dio XLVIII, 32,4. 
los amplissima collegia, y así entre los augures ${ }^{33}$ y $X V$ viri3 hay más descendientes de familias senatoriales, adlectos al patriciado y descendiente de ellos. Sin embargo todos los VIlviri son plebeyos, y de la mayoría de ellos sus orígenes son desconocidos $^{35}$. Es en este último sacerdocio donde se observa cómo de nuevo era fundamental el apoyo imperial para estos senadores que no tenían el respaldo de una familia bien asentada en la Curia. La mayoría de las carreras de estos VIIviri, a veces mal conocidas, refieren en algún momento del cursus un favor imperial ${ }^{36}$. Así por ejemplo el caso de Valerius Quadratus ${ }^{37}$, quien figura como cuestor del emperador y tribuno candidato, justo antes de la pretura, en torno a la cual sería cooptado entre los VIIviri; o el de Caecilius Aemilianus ${ }^{38}$ quien sería VIIvir poco antes de ser cuestor del emperador; o Claudius Claudianus ${ }^{39}$ que lo sería en torno a la pretura tutelaría que también desarrolló como candidatus ${ }^{40}$. Se concluye por tanto que la procedencia de los VIlviri de origen africano sería más humilde que la de los pontifices, augures, o incluso los XVviri, pero ello no fue obstáculo para que consiguieran entrar en uno de los más importantes colegios, seguramente por el apoyo imperial del que se vieron favorecidos.

${ }_{33}$ Salvo Arrius Antoninus, hombre nuevo en la Curia, el resto procederían de familias senatoriales. Además dos de los descendientes de Antoninus, C. Arrius Calpurnius Frontinus Honoratus y C. Arrius Calpurnius Longinus pertenecerían al patriciado.

${ }^{34}$ Entre los XVviri tres formarían parte del patriciado L. Cornelius Salvius Tuscus, descendiente del jurista lulianus, y que sería promocionado al patriciado pues se documenta como Salius Palatinus en el 181 d.C.; L. Pullaienus Gargilius Antiquus, adlectus in patricias familias por Cómodo y Fulvius Plautianus, quien desde orígenes ecuestre sería promocionado por Severo.

${ }_{35}$ Aunque la falta de evidencias epigráficas pudiera influir en ello sólo se conoce el caso de Pactumeius Rufus, descendiente del primer cónsul africano. El resto seguramente no procederían de grandes familias senatoriales, por el contrario incluso habrían sido promovidos desde el ordo ecuestre, como en el caso de Claudius Claudianus. El propio Sex Caecilius Aemilianus, quien sería VIlvir Epulonum antes de la cuestura, era hijo también de un procurador ecuestre.

${ }^{36}$ La carrera de Postumius Festus no se conoce bien, pero se presupone que conseguiría estar bien ubicado entre la elite senatorial, pues gozaba de la amistad del buen patrocinador, Cornelius Fronto. Por otro lado se desconoce el caso de Aelius Secundinus, a quien se le atribuye el cursus referido en la inscripción de Thugga (CIL VIII 26577 a-C=ILTun 1420=Dougga 66ª). Tan sólo se sabe que fue cónsul, frater Arvalis y VIIvir, de lo que se deduce que debió de estar bien considerado entre la elite social.

37 CIL VI, 1533; CIL VIII, 11811; CIL VIII, 27772; CIL VIII, 27776; PIR V, 124; PELLETIER, A., Op. Cit., p. 519, no97; CEBEILLAC, Mireille, Les quaestores principis et candidati aux ler et Ile siècles de l'empire, Milan, Cisalpino-Goliardica, 1972, pp. 149ss, no 68; CORBIER, M., Les familles clarissimes d'Afrique...pp. 708-709. Apéndice documental: $\mathrm{n}$ 느.

38 PIR² C 16; PELLETIER, A., Op. Cit., p. 513, nำ16 ; ALFÖLDY, Géza, Fasti Hispanienses. Senatorische Reichsbeamte und Offiziere in den spanischen Provinzen des römischen Reiches von Augustus bis Diokletian, Wiesbaden, Steiner, 1969, p. 173; CORBIER, M., Les familles clarissimes d'Afrique...p. 735 ; LEUNISSEN, P.M.M., Op. Cit., pp. 158, 297, 402. Apéndice documental: ํㅡ22.

${ }^{39}$ CIL VIII 5349= ILAIg. I, 279, PIR ${ }^{2}$ C 834; LE GLAY, (1982) «Senateurs de Numidie et des mauretanies», Epigrafía e ordine Senatorio, Tituli 5, Ed. di Storia \& Letter, Roma, 1982, p. 764; FITZ, Jenö, Die Verwaltung Pannoniens in der Romerzeit, Budapest, Encyclopedia, 1993, p. 512, ํㅜ 300; SALCEDO de PRADO, Isabel, «El senador de Cirta Ti. Claudius Claudianus y su familia: un ejemplo de integración» en RODRíGUEZ NEILA, Juan Francisco, MELCHOR GIL, Enrique (eds.) Poder central y autonomía municipal: la proyección pública de las élites romanas de Occidente, Córdoba, Universidad de Córdoba, pp. 211-225. Apéndice documental: no28.

40 Después de haber sido promocionado desde el ordo ecuestre, de donde debe explicarse su previo sacerdocio entre los Laurentes Lavinates. 
Como se observa el conjunto africano demuestra que era imprescindible el favor del emperador para lograr ser cooptado en alguno de estos collegia. Sin embargo habitualmente el emperador también respetaba el derecho de las familias que por su prestigio y antigüedad aspiraban a estos honores ${ }^{41}$. La familia y la antigüedad eran gravosas marcas que facilitaban la entrada y permanencia en la elite social y religiosa romana, y ello frenó sin duda la inclusión africana en este grupo social. Como se va a demostrar el caso africano está salpicado de figuras relevantes que en ocasiones pudieron acceder a esta «marca de status», pero que en su mayoría no consiguieron cuajar en una continuidad generacional.

Excepcional en este sentido es el caso de los Arrii, quienes generacionalmente ocuparon el augurado hasta en tres ocasiones. El primer miembro de esta familia en ser cooptado en el colegio augural fue $C$. Arrius Antoninus ${ }^{42}$. Previamente había sido incorporado a los fratres Arvales, justo tras su pretura, cuando despuntaba ya como un hábil jurista. Antoninus se había ganado la confianza de Marco Aurelio ${ }^{43}$, quien le había elegido como modelo para inaugurar algunas magistraturas de carácter administrativo-judicial, como la pretura tutelaria y la judicatura de la Traspadana. Su cercanía al emperador, y la pericia demostrada, fueron el aval suficiente para conseguir ser cooptado entre los augures, y posteriormente entre los sodales Antoninianit ${ }^{4}$. Sin embargo, Antoninus cayó en desgracia a finales del gobierno de Cómodo ${ }^{45}$, y víctima de las intrigas internas sería condenado y asesinado. Años más tarde, en época Severa un Arrius Honoratus restituiría el honor de su familia. Probablemente se trate de C. Arrius Calpurnius Frontinus Honoratus $^{46}$, descendiente de Antoninus, posiblemente su nieto. Éste sería elevado al

41 SAQUETE, J.C., Op. Cit., pp. 306-307.

42 PIR A 1088; LE GLAY, M., Op. Cit., pp. 763-764. Apéndice documental: noำ.

43 Arrius Antoninus gozó de la amistad de uno de los más influyentes personajes del momento, su compatriota M. Cornelius Fronto (PFLAUM, Hans Georg, «Les correspondants de l'orateur M. Cornelius Fronto de Cirta», Latomus 70, (1964), pp. 545-546; CHAMPLIN, Edward, Fronto and Antonine Rome, Cambridge, Mass. Harvard University Press, 1980, p.15) Fue por su mediación como Antoninus contó con la confianza de Marco Aurelio, quien le eligió para ensayar una nueva función pretoria, nombrándole praetorius tutelarius, siendo a continuación iuridicus per Italiam regiones Transpadanae primo (CORBIER, Mireille, «Les circonscriptions judiciaires de l'Italie, de Marc-Aurèle à Aurélien», MEFRA, 85, 2, (1973), pp. 632 y 635s) Su buen hacer y sus conocimientos jurídicos encumbraron la carrera de Antoninus, quien alcanzaría el consulado hacia el 170, varios gobiernos consulares y el proconsulado de Asia (188-189 d.C.) CORBIER, Mireille, L'Aerarium Saturni et l'aerarium militaire: administration et prosoprographie sénatoriale, Roma, Ecole Française de Rome, 1974, p. 264; ALFÖLDY, Géza, Konsulat und Senatorenstand unter den Antoninen. Prosopographische Untersuchungen zur senatorischen Führungsschicht, Bonn, Habelt, 1977, p. 317; PISO, Ioan, Fasti provinciae Daciae, Bonn, Habelt, 1993, pp. 112, 115-117.

44 RÜPKE, Op. Cit., no 711 , nt. 4 explica que pese a que en la inscripción CIL VIII 7030 es recordado como sodalis Marcianus Antoninianus, la titulatura del sacerdocio respondería al momento de dedicación de la inscripción, no al de la cooptación de Antoninus que seguramente fue previa.

45 LEUNISSEN, P.M.M., Op. Cit., p. 399.

46 Posiblemente identificado con el Arrius Honoratus quien restituiría el honor de su familia (Ulp. Dig. 36, 1, 38, 1; MILLAR, Fergus, The Emperor in the roman world (31 b.C.-a.D. 337), Ithaca, Cornell University Press, 1977, p. 534; DIETZ, Karlheinz, Senatus contra principem: Untersuchungen zur senatorischen Opposition gegen Kaiser Maximinus Thrax, Múnich, Beck, 1980, p. 87; LEUNISSEN, P.M.M., Op. Cit., p. 184). Puede identificarse con el nieto de Arrius Antoninus, aunque el grado de relación no es del todo seguro, cfr. en este sentido PIR² A, 1088-9, stemma 214, DIETZ, K., Op. Cit., 1980, pp. 85-87, 366; CORBIER, M., Les familles clarissimes d'Afrique..., pp. 709-710; LE GLAY, M., Op. Cit., pp. 763-764; 
patriciado y cooptado también entre los augures ${ }^{47}$, desarrollando al mismo tiempo una carrera puramente patricia que culminaría con el consulado en tiempos de Alejandro Severo ${ }^{48}$. De igual modo el hijo de este último, C. Arrius Calpurnius Longi$n u s^{49}$ sería introducido en el colegio de los augures poco después de su pretura y antes de revestir el consulado en tiempos de Gordiano III ${ }^{50}$.

El de los Arrii es un plástico ejemplo del interés de la familia en mantener un sacerdocio, sobre todo si, como en este caso, se trataba de la pertenencia al prestigioso colegio augural. Demuestra por tanto el afán de esta familia por conservar los méritos de sus antepasados, y de mantener su prestigio y dignidad de ser considerados entre los más romanos, los patricios, y entre su elite consular y religiosa. Pese a ello se trata de una familia de viva impronta africana que, formando parte intrínseca de la cumbre político-religiosa y social, no olvidó su lugar de origen, como así lo confirma el propio matrimonio de Arrius Calpurnius Frontinus Honoratus con una civis et patrona de Avioccala, Oscia Modesta ${ }^{51}$.

Sin embargo esta tendencia hereditaria apenas se observa en el resto del cuadro africano. Tan sólo, y no de forma hereditaria sino coetánea, se documenta el caso de dos Fulvii, ya que Fulvius Plautianus figuraría entre los XVviri probablemente desde el 203, y un año más tarde, en los ludi seculares del 204 se atestigua la presencia en el colegio de Fulvius Fuscus Granianus ${ }^{52}$. Este joven quaestor Augustorum ${ }^{53}$, sería probablemente promocionado mediante la influencia de su pariente ${ }^{54}$.

Dos únicos casos, y tan sólo el de los Arrii ampliamente documentado, canalizan las aspiraciones de los africanos por heredar o participar de los mismos sacerdocios de sus mayores. Esta aparente ausencia de continuidad familiar se hace más acuciante cuando se observa que no sólo es escasa la presencia de familiares en un mismo colegio sacerdotal, sino en el conjunto de los amplissima collegia. Es decir, salvo en los casos citados, y en el del XVvir sacris faciundis Cor-

RAEPSAET-CHARLIER, Marie-Thérèse (1987) Prosopographie des femmes de l'ordre sénatorial, ler.-lle. Siècles, Lovaina, Aedibus Peeters, 1987, I, p. 91s y II stemma XXXIII; BADEL, Christopher, C. (1994) Fasti Severiani. Etude sur le personnel administratif et politique de l'Empire romain de Caracalla à Sévère Alexandre (211-235), (Tesis doctoral) París, 1994, p. 43; SETTIPANI, Christian, Continuité gentilice et continuité familiale dans les families sénatoriales romaines à l'époque impériale: mythe et réalité, Oxford, Unit for Prosopographical Research, 2000, p. 96. Apéndice documental: nํ41.

47 Aunque BADEL, C., Op. Cit., p. 43 distinguía a dos personajes homónimos: aquel que hubiera muerto joven tras ser adlectus inter patricias familias (CIL VI, 3827), y su hijo, que sería el cónsul y augur.

48 Aparece honrado en ILAfr. 279 como consularis memoriae vir, por lo que debió de morir poco después de su consulado, DIETZ, K., Op. Cit., p. 87 nt. 211; CORBIER, M., Les familles clarissimes d'Afrique..., p. 710; LEUNISSEN, P.M.M., Op. Cit., p. 184

49 PIR $^{2}$ A 1096; LE GLAY, Op. Cit., p. 763-764. Apéndice documental: n46.

50 CIL VIII 23831

51 CIL VIII 23832.

$52 \mathrm{PIR}^{2}$ F 539; CORBIER, M., Les familles clarissimes d'Afrique..., p. 722. Apéndice documental: n-34.

53 CEBEILlAC, M., Op. Cit., p. 229-230.

54 La onomástica lo pone en relación con Fulvius Plautianus, así como con los Granii de Leptis Magna, CORBIER, M., Les familles clarissimes d'Afrique..., p. 722. 
nelius Salvius Tuscus ${ }^{55}$, descendiente del pontífice lulianus, todos los africanos que ocuparon algunos de los sacerdocios mayores fueron los primeros y los últimos de sus familias en aspirar a tales honores.

Es cierto que hay varios que obviamente fueron los primeros de sus familias, pues eran hombres nuevos en la Curia, basta recordar a los dos pontifices documentados; pero igualmente serían nuevos el propio Arrius Antoninus, primogénito de la escalera hereditaria del augurado, probablemente varios XVviri, como el adlecto Claudius Candidus ${ }^{56}$, o los VIlviri Caecilius Aemilianus ${ }^{57}$ y Claudius Claudianus ${ }^{58}$. Sin embargo también otros procedían de familias senatoriales, e incluso consulares, como el patricio L. Pullaienus Gargilius Antiquus ${ }^{59}$, pero son igualmente los primeros y los últimos de sus familias en ocupar uno de estos sacerdocios.

Por tanto, salvo en contadas ocasiones como la de los Arrii, no se atestigua ni herencia ni continuidad dentro de los africanos que accedieron al amplissima coIlegia. Cierto es que muchos son los últimos miembros conocidos de sus familias, sin haber trascendido apenas dos generaciones en la mayoría de los casos. Pero incluso cuando se rastrea la continuidad familiar no se atestigua su permanencia como miembros de la elite religiosa ${ }^{60}$. Esto lleva a pensar que o bien no tuvieron interés o es que carecieron de la oportunidad de acceder a estos sacerdocios.

Es difícil creer que un conjunto social en creciente promoción desde mediados del siglo segundo no quisiera voluntariamente optar a estos honores, que por otra parte, como se ha explicado, teñían sus figuras de una pátina distintiva frente a sus iguales. Entonces, ¿cómo explicar esta ausencia de continuidad en el orden religioso? Por una parte, como se ha comentado, por la propia falta de continuidad generacional en el caso africano, salpicado de importantes figuras de la actividad

55 PIR² C 1433; PELLETIER, A., Op. Cit., p. 514, no 29; CORBIER, M., Les familles clarissimes d'Afrique..., p. 720. Formaría parte de los Salii Palatini desde el 181 y sería XVvir en el 204. Apéndice documental: $\mathrm{n} \div 24$.

${ }^{56}$ Antes de ser adlecto por Cómodo desarrollaría una carrera ecuestre, cfr. PFLAUM, Hans-Georg, Les carrières procuratoriennes ... ํㅡㄴ 203; DEVIJVER, Hubert, Prosopographia militiarum equestrium quae fuerunt ab Augusto ad Gallienum, Lovaina, Universitaire Pers, 1976-1993, C no 128; FITZ, J., Op. Cit., 1993, pp. 628-630, no 355; SALCEDO de PRADO, I., Op. Cit., p. 219 s.

57 Apéndice documental: $\mathrm{n}$ 을.

58 Apéndice documental: nำ28.

59 L. Pullaienus Gargilius Antiquus habría sido adlectus inter patricias familias, estaría docuementado como XVvir en el 204 y descendería de los Pullaieni Gargilii consulares de Thugga.( AE 1916, 118; PIR ${ }^{2}$ G 80; PELLETIER, A., Op. Cit., p, 517, no69; CORBIER, M., Les familles clarissimes d'Afrique..., p. 737) Apéndice documental: no26.

60 Así por ejemplo el pontífice lulianus tendría un hijo, $P$. Salvius lulianus, que fue ordinario en el 175 y que además sirvió militarmente a Cómodo, pero cayó en desgracia y fue asesinado. Su carrera fue frenada, pero cierto es que para entonces era ya consular y podía haber sido cooptado por lo menos en algún colegio, pero no lo fue. El otro pontífice, Plautianus, corrió una suerte similar, y él mismo cayó en desdicha, acompañado por su hija, Plautilla, y su hijo Plautius Hortensianus, ambos exiliados y ejecutados posteriormente. Pudo acabar ahí la estirpe del prefecto del pretorio, y así se entendería que nadie hubiera podido aspirar a estos honores. Sin embargo quizá otra rama familiar pudo recuperar su fama, y así se explicaría el consulado ordinario en el 238 de C. Fulvius Pius, a quien la onomástica une con los Fulvii de Leptis Magna. Sin embargo este último senador, pese a formar parte de la elite consular, no figura como miembro de ningún colegio, aunque apenas se conoce su carrera. 
política de las que se desconoce su descendencia. $Y$ por otro lado una cosa era acceder al ordo senatorial, a puestos de responsabilidad, al consulado y otros gobiernos, y otra pasar a formar parte del grupo más selecto, más romano por su antigüedad y tradición ${ }^{61}$. Ciertamente convivió el favor imperial con el exclusivismo y el conservadurismo ${ }^{62}$, lo que hizo muy difícil la pervivencia generacional de los provinciales, y en este caso los africanos, entre esta elite religiosa ${ }^{63}$. A ello contribuyeron las dificultades que ya se comentaron para pertenecer a estos sacerdocios, entre otras la necesaria presencia de vacantes.

Así se explica a su vez que aunque algunas grandes personalidades del orden político como Salvius Iulianus, Arrius Antoninus, Claudius Claudianus, Claudius Candidus y Fulvius Plautianus consiguieran ingresar en estos collegia, otros pese a ser muy cercanos al emperador no lo hicieran. Se entiende así la ausencia de Cornelius Fronto ${ }^{64}$, el amigo de los emperadores, de Servilius Pudens ${ }^{65}$, casado con la hermana de Lucio Vero, de Cornelius Repentinus ${ }^{66}$, yerno de Didius Iulianus, de Clodius Albinus ${ }^{67}$, amigo primero y luego rival del lepcitano, o de grandes ge-

61 SAQUETE, J.C., Op. Cit. p. 330-331.

62 PFLAUM, H.G., Les prêtres du culte impérial...p. 208; SYME, R., Op. Cit., pp. 4-5.

63 SAQUETE, J.C., Op. Cit. p. 330-331.

64 Afamado orador, quien a través de sus competencias y valía intelectual ganaría un puesto de confianza en la corte imperial, sería maestro de los futuros emperadores Marco Aurelio y Vero, y adquiriría una influencia tal que motorizaría la promoción de clarísimos de Cirta. Cfr. CHAMPLIN, E. Op. Cit.; SALLER, Richard P., Personal Patronage under the Early Empire, Cambridge, Cambridge University Press, 1982, p. 185; MARTIN, J.P., «Fronton magister imperatorum», en ALONSO DEL REAL, Concepción, et Alii (eds.) Urbs aeterna, Actas y colaboraciones del coloquio internacional, Roma entre la literatura y la historia, Homenaje a la profesora Carmen Castillo, Pamplona, Eunsa, 2003, pp. 65-81) Él mismo trazó una rápida carrera, coronada por el consulado en el 142 dC., siendo elegido posteriormente para el proconsulado de Asia, aunque no pudo ejercer el cargo. Cfr. CIL VIII, $5350=$ ILAlg. I, $280=$ D 2928; CIL XI, 6334 = D 1129 = AE 1961, 244 = AE 1972, 173 = AE 2001, 17; PIR² C 1364; ALFÖLDY, G., Konsulat und Senatorenstand...pp. 36, 37, 59, 218; LE GLAY, M., Op. Cit., p. 765.

${ }^{65}$ Q. Servilius Pudens, de los Servilii de Hippo Regius, conseguiría casarse con la hermana de Lucio Vero, Ceionia Plautia, siendo elevado a la categoría de cónsul ordinario en el 166. Posteriormente sería procónsul de África (PIR ${ }^{2}$ S 595; CORBIER, M., Les familles clarissimes d'Afrique..., p. 721; THOMASSON, Bengt E. Fasti Africani. Senatorische und ritterliche Amtstrager in den romischen Provinzen Nordafricas von Augustus bis Diokletian, Estocolmo, Svenska Institutet i Rom, 1996, p. 71s, no 91.

${ }_{66}$ Sería adlectus inter praetorios por Marco Aurelio y Cómodo, entre el 177 y el 180, curator viae Flaminiae, desarrollando quizá luego algún otro cargo. A continuación sería gobernador de Lusitania, justamente antes de su consulado en el 188, y praefectus urbi. Contrajo nupcias con la hija del segundo emperador del 193, Didius Severus Iulianus, quien por línea materna también procedía de las tierras africanas. Cfr. CIL VIII, 15869; PIR² C 1427; ALFÖLDY, Géza, «(1968) «Septimius Severus und der Senat», Bonner Jahrbücher 168, (1968), p. 140; Ídem, Fasti Hispanienses..., p. 143; CORBIER, M., Les familles clarissimes d'Afrique..., p. 730.

67 Africano, de Hadrumetum, según la Historia Augusta, vit. Alb . 1.3; 4.1, aunque este aspecto, como otros referidos de su vida, puede ser ficticio. No obstante a favor de origen africano se señala la acuñación de moneda con la leyenda Saeculo Frugifero representante de Ba'al Hamon de Hadrumetum. Cónsul en el 188, tras el asesinato de Cómodo permaneció como gobernador consular en Britannia, convirtiéndose en un aliado de Severo, quien le otorgó el título de Caesar. Su alianza parecía confirmarse con el ejercicio conjunto de un segundo consulado en el 194, pero tras la caída de Niger la situación entre ambos cambió. Fue entonces cuando Albino se proclamó Augustus, siendo declarado enemigo público, y vencido en Lugdunum en el 197. PIR² C 1186; PELLETIER, A., Op. Cit., p. 514, no 27; CORBIER, M., Les familles clarissimes d'Afrique..., p. 719. 
nerales como Vettius Sabinianus Iulius Hospes ${ }^{68}$, o Marius Maximus ${ }^{69}$, estos dos últimos cooptados en sacerdocios de menor prestigio. De igual forma es llamativa la ausencia en este cuadro sacerdotal del hermano del emperador, $P$. Septimius Geta quien figura sin embargo entre los fetiales, colegio de mucho menor prestigio. Quizá esta ausencia de Geta entre los principales sacerdocios públicos entrase dentro de la política de Severo, quien no otorgó a su hermano puestos principales ni honras hasta prácticamente su muerte.

En definitiva, entre los africanos que optaron a estos sacerdocios mayores hay varios novi senatores, y otros de origen senatorial o incluso patricios, pero fueran cuales fueran sus orígenes todos formaron parte de le elite consular. Algunos fueron personajes políticamente muy activos e influyentes, pero salvo en el mencionado caso de los descendiente de Arrius Antoninus, ninguno dejó pervivencia de su honor por lo menos en este ámbito ${ }^{70}$.

Otra cuestión relevante en relación con la presencia africana en los quattuor amplissima collegia se refiere a su progresión temporal, de tal forma que antes de los Antoninos tan sólo un africano, Pactumeius Rufus ${ }^{71}$, debió de formar parte de uno de estos sacerdocios, en concreto sería VIlvir Epulonum. Bajo Antonino Pío y Marco Aurelio cinco asumirían estos deberes sacerdotales, mientras que desde Cómodo a Severo incluido ocho africanos estarían documentados entre los prin-

68 C. Vettius Sabinianus Iulius Hospes desarrolló previamente dos milicias ecuestres, siendo entonces promocionado al ordo senatorial por Antonino Pío ILAfr. 281; DEVIJVER, H., Op. Cit, V no 80 y 76. Bajo Marco Aurelio sobresaldría como un militar experimentado en el limes danubiano, al tiempo que, destacaría en su servicio en la administración, alcanzando el consulado hacia el 175 d.C. Posteriormente desarrollaría un par de curatelas para servir a continuación en las provincias fronterizas del Danubio, donde tanta experiencia había adquirido. Así fue gobernador en Dalmacia (177-170) Dacia (180-182?) y Panonia Superior (183-185), siendo posteriormente nombrado procónsul de África (190-191). Cfr. ILAfr. 281; CIL VIII, 823; PIR V 339; PELLETIER, A. , Op. Cit., p. 525, no 165; CORBIER, M., Les familles clarissimes d'Afrique..., p. 734; ALFÖLDY, G., Konsulat und Senatorenstand...pp. 190, 338.

69 L. Marius Maximus Perpetuus Aurelianus fue un memorable general aunque también sería conocido como un afamado escritor e historiador; sin embargo la magnitud de su obra suscita cierta controversia, pues algunos creen que es el fundamento de la Historia Augusta, mientras que otros piensan que es una fuente secundaria (BIRLEY, Anthony Richard, «Marius Maximus: the consular biographer», Aufstieg und Niedergang der römischen Welt, II, 34.3, Berlín-Nueva York, 1997, de Gruyter, pp. 2708 ss.) Gozaría de la amistad de todos los emperadores de su tiempo, convirtiéndose en un fuerte sustento militar de Septimio Severo, aunque posteriormente también contaría con el apoyo de Macrino y de Alejandro Severo (CROOK, J., Op. Cit., p. 74 n 226.) Desarrolló una carrera especialmente notoria, coronada por un segundo consulado ordinario (223 d.C.) y la prefectura de la ciudad, después de haber ejercido, entre otros cargos, los proconsulados de Asia y África. Cfr. CIL VI, 1450=D 2935; PIR² M 308; BIRLEY, Anthony Richard, Septimius Severus: The African Emperor, Londres, 1999 (3ª ed.), Londres, Routledge, p. 205, no4; Ídem, Marius Maximus...pp. 2679, 2755; SYME, Ronald, (1971) Emperors and biography, studies in the «Historia Augusta», Oxford, Claredon Press, 1971, pp. 135-143.

70 La mayoría de ellos alcanzarían el consulado, salvo Valerius Quadratus, Caecilius Aemilianus y Fulvius Fuscus Granianus, cuyas carreras sólo son conocidas hasta la pretura o cuestura, en el caso de Granianus. A su vez, son desconocidos los cursus de Pactumeius Rufus y Cornelius Salvius Tuscus; pero el resto de africanos documentados como miembros de los amplissima collegia alcanzaron las fasces consulares.

71 Documentado como VIlvir Epulonum bajo Trajano, sería el primer africano en ingresar en los quattuor amplissima collegia. PIR² P 40; LE GLAY, M., Op. Cit. p. 767. Apéndice documental: no2 
cipales sacerdocios públicos. Es reseñable la concentración de XVviri en estos momentos, pues seis están atestiguados durante el gobierno de Severo ${ }^{72}$. Sin embargo varios de ellos podrían pertenecer al colegio con anterioridad al alzamiento de Severo, pero en el caso de Claudius Candidus y Fulvius Plautianus está claro que fueron sus servicios el aval para ser promocionados hasta este sacerdocio, favorecidos quizá por las bajas que ocasionaron los diferentes frentes bélicos.

Después de Severo y hasta Galieno se conocen otros cinco africanos, cuatro de ellos augures, todos ya descendientes de familias senatoriales, incluso patricias. Por tanto, el cuadro relativo a la presencia africana en los principales sacerdocios públicos es paralelo a su inserción político-social. Es decir, esta presencia es tímida hasta los Antoninos, progresiva bajo éstos, alcanzando su culmen bajo Severo, y experimentando después un leve descenso, pero ya de miembros de familias consolidadas.

\subsection{Los sacerdotia minora}

Al margen de la pertenencia a unos de los cuatro principales collegia, donde como se ha explicado era difícil y selectiva su cooptación, los senadores romanos podían aspirar a formar parte de alguna otra sodalitas, o asociación religiosa, que también de forma diferenciada otorgaba honor y prestigio. Entre los africanos hay una mayor presencia entre estos sacerdocios menores que entre los quattuor amplissima collegia, cuestión que evidencia la naturaleza de la mayoría de los documentados $^{73}$.

Dentro de estas sodalidades también hay una jerarquización distintiva, y así unas de las más prestigiosas eran las de los Salii Palatini y Collini, donde era requisito fundamental para la cooptación el contar con un prestigioso origen. Estas sodalitates estaban formadas cada una por doce miembros y fueron creadas en los albores de la formación de la ciudad, los Salii Palatini para dar culto a Marte y los Collini que servían a Quirino. Al comienzo y al final de la estación dedicada a la guerra los Salii conducían procesiones victoriosas por la ciudad, realizaban diferentes ritos, bailaban y cantaban antiguas canciones (carmen Saliare) agitando sus lanzas y escudos.

72 Varios de ellos están documentados como XVviri en los ludi seculares del 204.Cfr. Apéndice documental: Q. Aiacius Modestus Crescentianus (nำ3), L. Cornelius Salvius Tuscus (nำ14), L. Pullaienus Gargilius Antiquus (n26), Iulius Pompeius Rusonianus (n27), C. Fulvius Plautianus (no33), Fulvius Fuscus Granianus (nำ34). Ti. Claudius Claudianus (n-30) también fue XVvir en estos momentos. Sobre la actas en los ludi seculares del 204 y la presencia de los XVviri, cfr. SCHUMACHER, L., Die vier hohen römischen Priesterkollegien..., pp. 727-737.

73 Además de los que se exponen a continuación hay un senador anónimo ( $\mathrm{n}$ ㄴ5) documentado como Sacer[doti...], y L. Cassius Manilianus (no49), como curio minor (AE 1990, 438). Este último sacerdocio estaba destinado normalmente a caballeros, pero también se atestiguan algunos senadores. Cfr. SCHEID, John, GRANINO CECERE, Maria Grazia, «Les sacerdoces publics équestres», en DEMOUGIN, Ségolène, DEVIJVER, Hubert, RAEPSAET-CHARLIER, Marie-Thérèse (eds.) L'Ordre équestre : histoire d'une aristocratie (Ilème siècle av. J.-C.-IIlème siècle ap. J.-C.), Roma, École française de Rome, 1999, p. 11. 
Este arcaico sacerdocio gozó de gran prestigio en época imperial, fundamentalmente porque sus miembros eran jóvenes patricios, avalados por sus padres, que debían seguir vivos en el momento de su cooptación. Este sacerdocio por tanto sellaba la carrera de un senador desde sus comienzos, enfatizando su pertenencia a las familias más antiguas, las patricias, y a su elite religiosa. Se recibía el sacerdocio de por vida, pero normalmente sus miembros lo dejaban cuando alcanzaban el consulado o eran cooptados en algún otro sacerdocio, como ocurría a menudo.

Entre los africanos, no son particularmente abundantes las familias patricias, y éstas datan de época de los Antoninos en adelante, cuando el componente africano empezó a formar parte evidente y consolidado dentro de la curia romana ${ }^{74}$. Así el primer Salio conocido de origen africano es L. Antistius Burrus Adventus ${ }^{75}$, cooptado entre los Salii Palatini en el $178^{76}$. Sin duda este joven clarísimo pertenecía a la familia del gran general de Marco Aurelio Q. Antistius Adventus Postumius Aquilinus ${ }^{77}$. Pese a que muchos no lo consideran pudiera tratarse del hijo de éste ${ }^{78}$, casado posteriormente con la hija del emperador, Vibia Aurelia Sabina, cuestión que justificaría la promoción de la familia entre los patricios. Los demás Salii Palatini serían cooptados en los últimos años de Cómodo, o durante el gobierno de Severo, y serían el fruto de los esfuerzos realizados por sus antepasados $^{79}$. Así Cornelius Salvius Tuscus ${ }^{80}$ debería su honra y promoción al jurista lu-

74 En cuanto a los africanos que figuraron entre los Salios, cfr. Apéndice documental: L. Antistius Burrus Adventus (nำ14), L. Cornelius Salvius Tuscus (nํ24), L. Annius Fabianus (nำ25), Vettius Sabinianus ( $\mathrm{n}-31$ ) y $Q$. Octavius Volusius Thuscenius ( $\mathrm{n} \div 47$ ), que figura entre los Collini. Además hay un Salius Palatinus [--]tus Bassillus (CIL VI, 1977; RÜPKE, J. Op. Cit., p. 717, no 391), datado cronológicamente en la segunda mitad del s.Il d.C., que algunos han identificado con M. Arranius Venustus Bassilianus, c.p. hijo de M. Arranius Venustus, de Ammaedara. Pero es una identificación muy hipotética, basada únicamente en la semejanza de uno de los cognomina. Además es poco probable que esta familia fuera patricia, pues el padre no es más que conocido como legado de la III Augusta y cónsul designado. Cfr. Ibídem, no391, nt.3.

75 Apéndice documental: no⒕

76 CIL VI, 1979.

77 PIR ${ }^{2}$ A 754; LE GLAY, M., Op. Cit., p. 769

78 Algunos han descartado la identificación del Salius Palatinus L. Antistius Burrus Adventus con el yerno de Marco Aurelio, L. Antistius Burrus, proponiendo que ambos serían primos o hermanos. Sin embargo, la semejanza onomástica propone con fundamento que se trate de la misma persona. El joven clarísimo habría sido ennoblecido y gracias al matrimonio con la hija del emperador habría promocionado extraordinariamente al consulado ordinario en el 181 d.C. Por eso lo más factible es que se trate del mismo personaje, y que realmente pueda hablarse de una promoción entre las familias patricias, pese que no sea aceptado por todos. A este respecto cfr. PIR ${ }^{2}$ A 757 y 758; BARBIERI, Guido, L'Albo senatorio da Settimio Severo a Carino: (193-285) Roma, A. Signorelli, 1952, no 643; PFLAUM, Hans-Georg, (1961) «Les gendres de Marc-Aurèle», Journal des Savants, n¹, (1961), p. 38; BERTRANDY, François, «Une grande famille de la confédération cirtéene.: les Antistii de Thibilis», Cahiers de Tunisie, XXIV, 1976, pp. 7-24; LE GLAY, M., Op. Cit, p. 770; RÜPKE, J., Op. Cit., p. 763 no 638 y 639.

79 En el caso del Salio L. Annius Fabianus (n-25) es más difícil determinar la causa de su promoción, pues sólo es conocido su abuelo homónimo, quien trazaría una carrera sencilla en tiempos de Antonino Pío. Si bien, algunos han relacionado a esta familia de Caesarea con los Annii patricios de origen hispano (LEUNISSEN, P.M.M., Op. Cit., p. 108)

80 Cfr. nt. 56. Apéndice documental: no-24. 
lianus, y Vettius Sabinianus ${ }^{81}$ al gran general y administrador Vettius Sabinianus lulius Hospes ${ }^{82}$.

A una cronología más avanzada pertenece el sacerdocio, como Salius Collinus, del patricio Q. Octavius Volusius Thuscenius ${ }^{83}$, de quien se desconocen los orígenes. Es precisamente en esta época, a finales del periodo estudiado, cuando hay una mayor concentración de patricios, miembros de estas familias cuyo prestigio se remontaba a tiempo de los Antoninos o de Severo. Sin embargo ninguno de estos patricios está documentado entre los Salios. Parece que ninguno de los Vettii que rondaron los consulados ordinarios a mediados de la tercera centuria optó a este sacerdocio revestido por su ancestro a finales de la centuria pasada ${ }^{84}$. Otra familia patricia de entonces, la de los descendientes de Arrius Antoninus, pusieron sin duda más empeño en pertenecer al colegio augural. Sin embargo, esto no hubiera sido óbice para haber recibido en su juventud este otro sacerdocio, ya que era normal que los Salii pertenecieran en su madurez a algún otro colegio, y dado su prestigio e influencia, era habitual que fuera uno de los cuatro principales ${ }^{85}$.

Parece por tanto que las familias patricias del siglo tercero de origen africano no consiguieron que sus jóvenes pertenecieran a los Salii. Como la falta de interés

81 Documentado como Salius Palatinus en el 199, aunque su nombre tan sólo se recuerda parcialmente [--]ius Sabinianus ( CIL VI, 1982, 4). Este Salio ha sido también identificado con Asinius Sabinianus (DIETZ, K., Op. Cit., p. 91, nt. 222; SETTIPANI, C., Op. Cit., p. 333), ahora conocido como M. Triarius Rufinus Asinius Sabinianus (IÇTEN, Çengiz, ENGELMANN, Helmut, «Inschriften aus Ephesos und Umgebung», ZPE 91, (1992), pp. 283-295). Sin embargo éste sería cónsul en torno al 225, por lo que en el 199 no debía tratarse más que de un puer, y además la ascendencia de este senador no auguraba tal éxito. Por otro lado parece mucho más probable por el éxito de su ancestro, Vettius Sabianianus lulius Hospes, así como por la certeza de la pertenencia al patriciado de sus descendientes, que el Salius Palatinus sea un miembro de los Vettii de Thuburbo Maius. Sin embargo no se puede identificar con el cónsul ordinario del 221 d.C., C. Vettius Gratus Sabinianus, quien en aquellos momentos no sería más que un niño. Sí podría tratarse de un miembro de una generación intermedia omitida en la inscripción africana CIL VIII, 823, tratándose bien del padre del ordinario del 221 o mejor un pariente cercano. En cualquier caso es muy probable que sea en esos momentos cuando se produjo la promoción de la familia al patriciado, por lo que es una hipótesis muy atractiva considerar al Salio como miembro de esta estirpe. En torno a la identificación de este sacerdote, cfr. en general CORBIER, M., L'Aerarium Saturni...p. 277; DIETZ, K., Op. Cit., pp. 90-93 y 249; CHRISTOL, M., Essai sur l'évolution...,pp. 257-258; JACQUES, François, «L'ordine senatorio attraverso la crisi del III secolo», Società romana e Imperio tardoantico, vol. I., Bari, Laterza,1986, p. 219; SETTIPANI, C., Op. Cit., p. 333 y RÜPKE, J., Op. Cit., p. 1365, no 3474. Apéndice documental: $\mathrm{n} \div 31$.

82 Cfr. nt. 69.

83 CIL VIII 14312; PIR² O 64; PELLETIER, A., Op. Cit., p. 516, no 63; CORBIER, M., Les familles clarissimes d'Afrique..., p. 740. Apéndice documental: $\mathrm{n} \div 47$.

${ }^{84}$ Entre ellos estarían C. Vettius Gratus Atticus Sabinianus, cónsul ordinario en el 242 y Vettius Gratus, cónsul también ordinario en el 250 . Hay que recordar que en todo caso, salvo los consulados, las carreras de ambos son desconocidas

${ }^{85}$ Así se confirma en el caso de Cornelius Salvius Tuscus, quien figura entre los Salii Palatini desde el 181, pero quien en el 204 está documentado como miembro de los XVviri. Por otro lado L. Annius Fabianus pudo haber ejercido algún otro sacerdocio, aunque no está documentado. En el caso de $L$. Antistius Burrus Adventus, se entendería que no ejerciera ningún otro sacerdocio si, como se ha propuesto, fuera el mismo Antistius cuñado de Cómodo y ejecutado bajo el gobierno de éste. En cuanto a Vettius Sabinianus y Octavius Volusius Thuscenius se desconoce si pertenecieron o no a otro sacerdocio. 
no parece justificable, seguramente esta ausencia entre las filas de los Salii se pudo deber a la falta de vacantes, o a que no se cumplieron algunas premisas, como la necesidad de que los padres siguieran vivos. Pero lo que es obvio es que las probabilidades de pertenencia no fueron muchas porque aunque en esta época se documentan un mayor número de patricios de origen africano el número de estos no deja de ser simbólico.

Otro grupo sacerdotal de gran prestigio era la fraternidad de los fratres Arva$l e s^{86}$, de antigua organización, pero que gozó de renovada importancia tras las reformas augusteas. Estaba formado por doce sacerdotes que eran cooptados de por vida, y al frente del colegio estaba un magister que era elegido anualmente. Su culto estaba orientado a la fertilidad de los campos para lo que hacían sacrificios a la Dea Dia. Esta deidad femenina estaba relacionada con la bondad de la luz del cielo que permitía las buenas cosechas, y para conservar este orden los fratres Arvales le tributaban sacrificios en el mes de Mayo. En época imperial gozaron de una renovada significación, cuando Augusto vio en este culto agrario una conexión con el fundador de la ciudad, Rómulo, y en la honras a Dea Dia un símbolo de la legitimidad del princeps. Además su conocimiento viene facilitado por sus acta o commentarii, que reunían cada año las acciones y decisiones de la fraternidad.

Sin embargo, pese a la importancia de este sacerdocio la presencia africana es muy escasa. Probablemente su prestigio sería lo que dificultó la cooptación de los africanos, que como parece señalarse hasta ahora, no fueron los mejores candidatos pare revestir los sacerdocios principales. Tan sólo se documentan a lo largo de todo el periodo tres únicos casos que consiguieron acceder a esta fraternidad ${ }^{87}$. Apenas se conocen los datos biográficos de Annius Anullinus Geminus Percennianus ${ }^{88}$ y Aelius Secundinus ${ }^{89}$, y sólo está mejor documentado el ya mencionado, C. Arrius Antoninus ${ }^{90}$. Éste además llegaría a ser augur y miembro de una sodalidad imperial, y su prestigio ha sido ya comentado. En cuanto a Percenninaus y Secundinus cabe señalar que ambos pertenecen al avanzado siglo tercero y los dos alcanzaron el consulado ${ }^{91}$, pero no se sabe mucho más de ellos. De Percen-

${ }^{86}$ Sobre este sacerdocio, tanto sobre el estudio teórico como prosopográfico cfr. SCHEID, John, Les Frères Arvales....; Ídem, Le collège des frères arvales..; Ídem, Romulus et ses frères. Le collège des frères arvales, modèle du culte public dans la Rome des empereurs, París, Ecole Française de Rome, 1990; Ídem, Commentarii Fratrum Arvalium qui supersunt: les copies épigraphiques des protocoles annuels de la confrérie arvale (21 av.-304 ap. J.-C.), Roma, Ecole Française de Rome, 1998.

87 También está atestiguado como frater Arvalis un L. Claudius Modestus (CIL VI, 2086) a quien se le ha atribuido tradicionalmente una origo africana, pero que no parece segura. A su vez hay un $L$. Flavius Honoratus Lucilianus, magister de los fratres Arvales en el 240, considerado como cuiculitano por algunos (LE GLAY, M., Op. Cit., p. 771), pero que con mayor probabilidad descendería del caballero Flavius Lucilianus, atestiguado en Aveia Vestina (CIL IX, 3608, DIETZ, K., Op. Cit., no 156ss)

88 Apéndice documental: $\mathrm{n} \div 40$.

89 Apéndice documental: $\mathrm{n}$-42.

90 Apéndice documental: nำ12.

91 C. Annius Anullinus Geminus Percennianus sería cónsul en tiempos de Alejandro Severo, hacia el 228 d.C., y P. Aelius Secundinus bajo Maximino. 
nianus ${ }^{92}$ se advierte un posible origen ecuestre, y de Secundinus se presume que habría alcanzado una estabilidad entre la elite de la Curia, como parece indicar una inscripción de Thugga ${ }^{93}$, que le señala como miembro del los $X X$ viri nombrados por el Senado en contra de Maximino, y como VIlvir Epulonum.

También es escasísima la presencia africana entre los sodales Titii, antigua sodalidad que daba culto al legendario rey sabino Titius. Cuatro únicos casos están documentados entre Antonino Pío y Cómodo ${ }^{94}$. Todos ellos llegaron al consulado y ninguno obtuvo otro sacerdocio, como comenzó a ser frecuente entre estos sacerdotes en el siglo segundo ${ }^{95}$. Lo destacable del caso es que dos de ellos $C$. Iulius Geminius Capellianus ${ }^{96}$ y $P$. Iulius Geminius Marcianus ${ }^{97}$ pertenecerían a la misma familia, posiblemente serían hermanos ${ }^{98}$.

Entre los miembros de los quattuor amplissima collegia se observó la falta de continuidad y relación familiar entre los africanos, cuestión que se repite entre estos sacerdocios menores. Apenas se advierten este tipo de relaciones, que ahora entre los Titiii se subrayan tímidamente. Sin duda la relación entre ambos hermanos habría mediado en su pertenencia a esta antigua sodalidad, pero cabe destacar que en cualquier caso ninguno de estos Iulii Geminii dejó descendencia en este sentido, lo que ratifica esta falta de continuidad. Cierta herencia dejaría también Vettius Sabinianus Iulius Hospes, aunque no en el mismo sacerdocio, pues éste sería cooptado como sodalis Titius y, como se ha señalado, un descendiente suyo lo sería entre los Salios ${ }^{99}$.

Sin ser copioso es mayor el número de fetiales documentados ${ }^{100}$, hecho que contribuye a perfilar con mayor nitidez el conjunto de los africanos atestiguados, pues se trata de uno de los sacerdocios de menor prestigio. Este sacerdocio

92 Sería probablemente descendiente del Percennianus documentado como prefecto de la anona, cfr. PFLAUM, Hans-Georg, Les carrières procuratoriennes ... 1103; CASTILLO GARCíA, C., (1968) "Observaciones sobre la continuidad prosopográfica de la Bética en el Bajo Imperio», Actas del III Congreso Español de Estudios Clásicos, vol. II, Madrid, Soc. esp. de Estud. clás., 1968, pp. 123-125; KOLB, Anne, Die kaiserliche Bauverwaltung in der Stadt Rom: Geschichte und Aufbau der "cura operum publicorum» unter dem Prinzipat, Stuttgart, Steiner, 1993, p. 262.

${ }_{93}$ CIL VIII, 26577a-C = ILTun 1420 = Dougga 66; KHANOUSSI. Mustapha, MAURIN, Louis (2000) Dougga, fragments d'histoire: choix d'inscriptions latines éditées, traduites et commentées, ler-IVe siècles, Burdeos-Túnez, Ausonius-INP, 2000, p. 174ss, no 66 .

94 Apéndice documental: C. Iulius Geminius Capellianus (nํ), P. Iulius Geminius Marcianus (nำ13), C. Vettius Sabinianus Iulius Hospes ( $\mathrm{n}-15)$, C. Memmius Fidus Iulius Albius ( $\mathrm{n} \div 19$ )

${ }_{95}$ Con anterioridad normalmente se documentaban en combinación con otros sacerdocios, RÜPKE, J., Op. Cit., p. 22.

96 Cónsul entre el 161 y el 162 d.C., PIR ${ }^{2}$ I 339; LE GLAY, M., Op. Cit., p. 766.

97 Cónsul hacia el 164-165 d.C. PIR² I 340; ALFÖLDY, G., Konsulat und Senatorenstand...p. 243; LE GLAY, M., Op. Cit., p. 766.

98 DIETZ, K., Op. Cit., pp. 166-167; LE GLAY, M., Op. Cit., p. 766.

99 Cfr. nt. 82.

100 Están documentados ocho africanos en este sacerdocio. Apéndice documental: Q. Aurelius Pactumeius Fronto (nำ1), P. Pactumeius Clemens (nํ), Q. Lollius Urbicus (n4), M. Servilius Fabianus Maximus (n6), Q. Antistius Adventus Postumius Aquilinus (nํ11), P. Septimius Geta (n16), M. Asinius Rufinus Valerius Verus Sabinianus (nำ18), L. Marius Maximus Perpetuus Aurelianus (nำ32) 
hundía sus raíces en la más temprana formación de la ciudad, y los miembros de su collegium estaban encargados de velar por las relaciones con otros pueblos vecinos, sancionando la justicia de la guerra y de la paz, conservando el ius fetiale $e^{101}$. Sin embargo, pese a la importancia que pudieran tener en época republicana cuando Roma se extendía por toda la cuenca mediterránea, en el Imperio perdieron su notoriedad y pasó a ser uno de los sacerdocios menos representativos. El número de miembros era mayor que el de otros colegios, veinte, y su menor importancia pudo facilitar la entrada de los africanos, al no encontrar tanta competitividad para ello.

La mayoría de los africanos que optaron a este sacerdocio provenían de humildes orígenes, pero lo relevante del caso es que varios de ellos fueron hombres cercanos al emperador, y que gozaron a lo largo de sus carreras de un especial favor. Así es por ejemplo en el caso de Q. Aurelius Pactumeius Fronto ${ }^{102}$, el primer senador que fue fetialis ${ }^{103}$. Cabe señalar que había sido adlecto en la censura de Vespasiano y Tito (73-74 d.C.) y se había convertido también en el primer consular africano ${ }^{104}$. Mucho más cercana fue la relación del fetialis Lollius Urbicus con Adriano ${ }^{105}$, pues antes de ser cooptado en el colegio ya había sido favorecido por su apoyo en el tribunado de la plebe y la pretura, después de la cual había recibido importantes responsabilidades militares. Otro militar, de tiempos de Antonino Pío que fue cooptado entre los fetiales fue Antistius Adventus ${ }^{106}$. Ya se ha comentado el caso del hermano del emperador, $P$. Septimius Geta ${ }^{107}$, pero paradigmático es también el de Marius Maximus ${ }^{108}$, hombre de confianza de Severo,

${ }^{101}$ Cic. Off. I, 36; Liv. IX, 9. Sobre su funcionalidad y rito durante época republicana cfr. WIEDEMANN, Thomas, «The Fetiales: A Reconsideration,» The Classical Quarterly, New Series, 36.II, (1986), pp. 478-490.

102 PIR $^{2}$ P 38; LE GLAY, M., Op. Cit., p. 767.Años más tarde, el descendiente de Q. Aurelius Pactumeius Fronto ( $\mathrm{n}-1$ ), el experto jurista Pactumeius Clemens ( $\mathrm{n}-3)$, quiso también formar parte del mismo colegio sacerdotal que su tío abuelo. Sin embargo, su posible padre o al menos pariente, Pactumeius Rufus (nำ), había conseguido ingresar en el colegio de los epulones.

103 Apéndice documental: $\mathrm{n}$ ⒈

104 Consul ex Africa primus (CIL VIII 7058=ILS 1001=ILAIg II, I, 644)

105 Q. Lollius Urbicus, natural de Cirta, está atestiguado en un mausoleo familiar junto a otros miembros de su familia (CIL VIII 6705 = ILAlg. II, 3563), pero tan sólo él está documentado como senador. Contó con el favor de Adriano y posteriormente de Antonino Pío, desarrollando una carrera de eminente responsabilidad militar. Alcanzaría el consulado hacia el 135, recibiendo a continuación los gobiernos de Germania Inferior y Britania, donde demostraría nuevamente sus habilidades militares, consiguiendo ser el primer africano que fue nombrado prefecto de la ciudad. CIL VIII 6705 = ILAlg. II, I, 3563; CIL VIII 6706 = ILAlg, II, I, 3605 = D 1065; ILAlg, II, I, 3446; PIR² L 327; LE GLAY, M., Op. Cit., p. 768.Apéndice documental: $\mathrm{n}$-4.

${ }_{106}$ Q. Antistius Adventus Postumius Aquilinus era nativo de Thibilis, localidad cercana a Cirta, y muy probablemente pudo contar con el apoyo del orador en la Curia para obtener la confianza y cercanía de Marco Aurelio, llegando a casar a su hijo con la hija pequeña de éste. Adventus desarrollaría una importante carrera demostrando su valía como comandante, en particular en la expeditio parthica. Tras el consulado (166 o 167 d.C.) fue elegido por Marco Aurelio para dirigir las tropas que defenderían la península itálica de las razias enemigas de cuados y marcomanos, en plena expeditio germanica (168-170). Seguidamente repetiría el cuadro ya habitual de los hombres militares, siendo primeramente gobernador en Germania Inferior, y posteriormente en Britania. PIR ${ }^{2}$ A 754; LE GLAY, M., Op. Cit., p. 769. Apéndice documental: nำ11.

107 Apéndice documental: $\mathrm{n} \cong \mathbf{1 6}$.

108 Cfr. nt. 70. 
quien contó con todos los méritos y honores del cursus, hasta la prefectura de la ciudad y un segundo consulado, pero que tan sólo es recordado como fetialis ${ }^{109}$.

En conclusión, todos estos fetiales llegaron al consulado, la mayoría gobernaron provincias consulares, e incluso cabe decir que de los tres africanos conocidos que ejercieron la prefectura de la ciudad, dos pertenecen a este colegio sacerdotal ${ }^{110}$. Por eso es extraño que estas figuras de la política imperial tan sólo se encuentren representadas en este sacerdocio ${ }^{111}$. De nuevo hay que recurrir a pensar que no siempre fue suficiente la influencia imperial para entrar en el grupo de las más selectas y antiguas familias, que en el plano religioso trascendía en el ejercicio de los más importantes sacerdocios ${ }^{112}$.

Además coincide que estos fetiales están atestiguados en los primeros momentos de la inmersión africana en la Curia, perteneciendo un único caso a tiempos de Severo y siendo inexistentes a continuación. Ello dibuja la primera promoción africana que en virtud de sus méritos consiguió ingresar al menos en un colegio sacerdotal, aunque este no fuera de los más prestigiosos. La pena es que, aunque las fuentes pudieran revelar nuevos datos, sus esfuerzos quedaron ahí, pues apenas se documentas miembros de sus familias que siguieran esta promoción. Tan sólo, como se ha señalado, un descendiente de Antistius Adventus, L. Antistius Burrus Adventus ${ }^{113}$, es conocido después como Salius Palatinus, debiendo su alta posición social a los esfuerzos previos de su familiar.

Como nota común a todos estos sacerdocios menores cabe destacar que salvo en el caso de los Salii, la mayoría fueron ejercidos por hombres nuevos cuyos anhelos se vieron saciados con el acceso a sodalitates de menor prestigio, como la de los fetiales o sodales de alguna divinidad imperial. Estos últimos fueron creados bajo la misma estela que los sodales Titii, pero en época imperial para el culto de los emperadores y sus familias.

Todos los sacerdocios públicos experimentarían una revisión con la llegada del nuevo régimen imperial, pero sin duda, lo que cambió definitivamente la religión pública romana fue la creación de todo un complejo sacerdotal que debía encargarse del culto a los emperadores. Sin entrar aquí en la difusión necesaria del culto imperial, cabe destacar entre los sacerdocios públicos romanos la creación de flaminados y sodalidades destinados a esta función. Apenas está documentado un flamen entre los africanos, y su propuesta no es del todo segura ${ }^{114}$; sin embargo

\footnotetext{
109 Apéndice documental: $\mathrm{n}$ 으.

110 Es el caso de Lollius Urbicus, praefectus urbi (146-160?d.C) y Marius Maximus (218 d.C.)

111 Ningún fetialis africano acumuló otro sacerdocio.

112 Sobre el conservadurismo en el ejercicio de los sacerdocios públicos romanos SAQUETE, J.C., Op. Cit., pp. 330-331.

113 Cfr. nt. 79.

114 M. Postumius Festus (n־9) es recordado como flamen (CIL VI, 1416=D 292). RÜPKE, J., Op. Cit., p. 1234, no 2826 propone que quizá se trate de un flamen Ulpialis. A su vez Aemilius Frontinianus (nำ17) también pertenecería a un grupo sacerdotal encargado del culto imperial, pues es recordado como miembro del ordo de los sacerdotes domus Augustae Palatinae. Sobre estos sacerdocios RÜPKE, J., Op. Cit., pp. 24-25.
} 
están ampliamente atestiguados los sodales encargados del culto de las diferentes dinastías imperiales.

Las primeras sodalidades creadas en este sentido fueron las dedicadas a Augusto y sus descendientes, los encargados eran los sodales Augustales Claudiales. Luego nacerían los sodales Flaviales Titiales, sodales Hadrianales, y sodales Antoniniani. Los Augustales gozaron tradicionalmente de un mayor prestigio, aunque a partir de Marco Aurelio el reclutamiento entres éstos y los Flaviales fue menos brillante, pues adquirieron mayor dignidad las sodalidades de reciente creación ${ }^{115}$. Esto se corrobora en el conjunto africano, pues lo senadores de mayor prestigio fueron aquellos que participaron en las sodalidades que acababan de ser fundadas. Así C. Septimius Severus ${ }^{116}$ y Salvius Iulianus ${ }^{117}$ ingresaron en los sodales Hadrianales, pero este último fue cooptado también entre los sodales Antoniniani. Este tipo de acumulación de sodalitates imperiales no era frecuente, pero la unión del jurista con el emperador fue sin duda lo que lo propició ${ }^{118}$. De igual forma la influencia imperial habría mediado en la elección de Arrius Antoninus como sodalis Antoninianus $^{119}$, pese a que también era augur y arval. Fueron concretamente estos tres senadores, coetáneos a la fundación de las sodalitates a las que pertenecieron, los que mayor prestigio demuestran, pues los tres consiguieron formar parte de alguno de los quattuor amplissima collegia.

Son precisamente los fuertes lazos sostenidos en vida entre Antonino Pío y senadores como Cornelius Fronto y Servilius Pudens, lo que ha llevado a proponer que éstos fueran miembros fundadores de la sodalidad dedicada al emperador ${ }^{120}$. Ya se conocen los evidentes y estrechos vínculos mantenidos entre Fronto y Antonino Pío, o Servilius, marido de la hermana de Lucio Vero; pero su posición, su influencia y cercanía, que avalan esta hipótesis no la hacen necesaria. Falta lo primordial, y es que su pertenencia a dicha sodalidad no está atestiguada, como tampoco lo está a ningún otro sacerdocio, cuestión que dada la importancia de dichas figuras ya ha sido apuntada como relevante.

115 PFLAUM, H. G., Les sodales Antoniniani...p. 90.

116 La Historia Augusta cuenta como L. Septimius Severus conseguiría entrar en el Senado por la mediación de un familiar suyo (HA, vit. Sev. 1,5) el cónsul de época antonina $C$. Septimius Severus, bajo quien sería también legado en África (173-174 d.C.). PIR ${ }^{2}$ S 485, PELLETIER, A., Op. Cit., p. 518, no 84; CORBIER, M., Les familles clarissimes d'Afrique..., pp. 723-4. Apéndice documental: no7.

117 Cfr. nt. 22. Apéndice documental: no10.

118 Sobre la influencia del emperador como miembro fundador en la elección de sus miembros, cfr. PFLAUM, H. G., Les sodales Antoniniani...p. 90.

119 Apéndice documental: $\mathrm{n}$ 12 .

120 PFLAUM, H. G., Les sodales Antoniniani...p. 78 proponía a Fronto como uno de los miembros del recién creado colegio de los sodales Antoniniani (161); cfr. también STANTON, G. R. «Marcus Aurelius, Lucius Verus, and Commodus: 1962-1972», Aufstieg und Niedergang der römischen Welt, II.2, Berlín-Nueva York, de Gruyter, 1975, p. 527. Sin embargo RÜPKE, J., Op. Cit., 913, advierte que aunque así ha sido considerado tradicionalmente no es más que una hipótesis que no puede ser considerada. Lo mismo pasa con Q. Servilius Pudens (PFLAUM, H. G., Les sodales Antoniniani...p. 85) pero Rüpke señala que no es más que una hipótesis no refrendada. (RÜPKE, 2005, 1283) 
En cuanto al resto de sodales dedicados al culto imperial cabe destacar que la mayoría fueron sodales Augustales (Claudiales) ${ }^{121}$, y tres fueron Flaviales ${ }^{122}$. Sin embargo todos ellos se documentan a partir de Cómodo o Severo y hasta adentrado el siglo tercero, momento en el que, como se ha señalado, estas sodalidades ya no gozaban de la dignidad de antaño. Todo ello responde a que en su conjunto los africanos así documentados proceden de humildes orígenes y la proporción de aquellos que alcanzaron el consulado es cuantitativamente menor ${ }^{123}$.

Cabe concluir que la integración africana entre la elite sacerdotal fue paralela a la promoción política en cuanto a la procedencia geográfica de los clarísimos que alcanzaron estos honores. Las Mauritanias apenas están representadas entre los miembros de esta elite religiosa, mientras que la mayoría provienen de la Proconsular y especialmente de Numidia. Es sobre todo bajo los Antoninos, y durante el gobierno de Severo, cuando un activo contingente procedente de la región cirtense no sólo consiguió establecerse entre la elite intelectual y militar, sino también entre la elite religiosa.

Se observa por tanto cómo la integración africana es además paralela a la inserción política en cuanto al orden temporal, documentándose una presencia creciente desde los Antoninos, culminante bajo Severo y que pervivió después pero, salvo contados casos, sin el esplendor de antaño. Esto se debió a que los valiosos hombres que consiguieron acceder a estos sacerdocios, tanto los de mayor prestigio como los demás, apenas consiguieron dejar herencia de este honor entre su descendencia.

Este hecho se explica ya que, pese a la notoriedad política de muchos africanos y su proximidad al emperador, éste no era el único principio que regulaba la pertenencia a la elite religiosa. La tradición y el exclusivismo de estos grupos sacerdotales dificultaron en gran medida la pertenencia, y luego continuidad de estos jóvenes provinciales. Se entiende así que fuera todavía más difícil para los africanos acceder a los quattuor amplissima collegia, y que estén más documentados en el resto de sacerdocios, sobre todo en los de menor prestigio, entre los fetiales y sodales de alguna dinastía imperial.

121 Apéndice documental: Q. Caecilius Laetus (nำ1), Sex. Furnius Sulpicianus (nำ36), L. Insteius Tertullus (nำ), Q. Aradius Rufinus Optatus Aelianus (nำ), A. Terentius Pudens (n39). Sin embargo no se ha considerado a Castus cónsul del 130 y magister bis de los sodales Augustales en el 137 (CIL XIV 2390), quien había sido relacionado como ancestro de lulius Castus de Thibilis. Esta relación es muy hipotética, pues son varias las décadas que los separan y el único eslabón que les une es el cognomen Castus, muy extendido por otra parte. Tampoco se ha tenido en cuenta a Claudius Maximus, sodalis Augustalis (RÜPKE, J., Op. Cit., p. 885, № 1211). Algunos han propuesto una origo africana para este senador, argumentando una relación con los Claudii de Cirta, pero la pertenencia a esta gens no es razón sólida para considerarlo africano. LE GLAY, M., Op. Cit., p. 769; FITZ, J., Op. Cit., 1993, no 183.

122 Apéndice documental: Iunius [-] Gargilius (n-20), Porcius Optatus Flamma (n-29) y lunius Faustinus Postumianus ( $\mathrm{n}-35)$.

${ }_{123}$ Entre los Augustales y Flaviales, ocho en total, tan sólo se documentan los consulados de lunius [-] Gargilius (probablemente cónsul hacia el 191-192 d.C.), ), lunius Faustinus Postumianus (cónsul sufecto 204-205 d.C.) y Aradius Rufinus (cónsul hacia el 228 d.C.), aunque cierto es que se desconocen las carreras completas de algunos así documentados. 
Aunque el peso de la antigüedad y la pertenencia al patriciado, al tiempo que la necesidad de vacantes y otros factores explican la ausencia de algunas importantes figuras africanas, no deja de ser significativa la cuestión de por qué unos sí lo consiguieron y otros no. Un conjunto de méritos, coincidencias y posibilidades mediaron sin duda en la promoción entre esta élite de personajes como Arrius Antoninus, Fulvius Plautianus o Salvius lulianus, pero fue también su afán por identificarse con los idearios de Roma lo que lo hizo factible. Quizá otros, y se trata sólo de una hipótesis, no volcaron todos sus esfuerzos en ello. Así se entendería la ausencia por ejemplo de Cornelius Fronto, quien gozó de la amistad de Antonino Pío, y fue elegido como tutor de los futuros emperadores, Marco Aurelio y Lucio Vero, manteniendo una íntima relación con ellos. Además, gracias a su trascendente amistad, influyó positivamente en la promoción de sus conciudadanos, y consiguió él mismo trazar una rápida carrera, conquistando el consulado sin demasiado esfuerzo, y recibiendo en honor el proconsulado de Asia. O las fuentes se han perdido $^{124}$, o es que el orador Fronto no se empeñó en alcanzar esta «marca de status», pues está claro que influencias no le faltaron.

\begin{tabular}{|l|l|l|l|l|}
\hline \multicolumn{5}{|c|}{ APÉNDICE DOCUMENTAL } \\
\hline № & Cronología & Nombre & Sacerdocios & Origen \\
\hline 1 & Tito & $\begin{array}{l}\text { Q. Aurelius Pactu- } \\
\text { meius Fronto }\end{array}$ & Fetialis $^{125}$ & $\begin{array}{l}\text { Cirta } \\
\text { Numidia }\end{array}$ \\
\hline 2 & Trajano & Pactumeius Rufus & VIIvir Epulonum $^{126}$ & $\begin{array}{l}\text { Cirta } \\
\text { Numidia }\end{array}$ \\
\hline 3 & Adriano & $\begin{array}{l}\text { P. Pactumeius } \\
\text { Clemens }\end{array}$ & Fetialis & $\begin{array}{l}\text { Cirta } \\
\text { Numidia }\end{array}$ \\
\hline 4 & Adriano & $\begin{array}{l}\text { Q. Lollius Urbicus } \\
\text { Fetialis }\end{array}$ & $\begin{array}{l}\text { Cirta } \\
\text { Numidia }\end{array}$ \\
\hline 5 & Antonino Pío & $\begin{array}{l}\text { M. Valerius } \\
\text { Quadratus }\end{array}$ & VIIvir Epulonum ${ }^{129}$ & $\begin{array}{l}\text { Althiburos } \\
\text { Africa Proconsularis }\end{array}$ \\
\hline
\end{tabular}

${ }^{124}$ En este sentido se entiende la apuesta de PFLAUM, H. G., Les sodales Antoniniani...p. 78 que decía que Fronto debió de pertenecer a los sodales Antoninini. Aunque como ya se ha señalado, no es más que una hipótesis no documentada. 856 .

${ }_{125}$ Cooptado tras su adlectio inter praetorios. CIL VIII, 7058=D 1001; RÜPKE, J., Op. Cit., p. 807, no

126 AE 1936, 95; SCHUMACHER, L., Die vier hohen römischen Priesterkollegien..., p. 692, nำ13; RÜPKE, J., Op. Cit., p. 1187, no 2600.

127 Inmediatamente después del tribunado de la plebe (124). CIL VIII, 7059=D 1067; RÜPKE, J., Op. Cit., p. 1187, ํㅜ 2598.

${ }_{128}$ Cooptado justo antes o durante su consulado. CIL VIII, 6706=ILAlg II, 3605=D 1065; RÜPKE, J., Op. Cit., p. 1117 , no 2282 .

${ }_{129}$ En torno a la pretura (ca.150). CIL XIV, 3996=CIL VII533; RÜPKE, J., Op. Cit., p. 1356, no 3428. 
La participación de los senadores de origen africano...

\begin{tabular}{|c|c|c|c|c|}
\hline 6 & Antonino Pío & $\begin{array}{l}\text { M. Servilius Fa- } \\
\text { bianus Maximus }\end{array}$ & Fetialis $^{130}$ & $\begin{array}{l}\text { Hippo Regius } \\
\text { Africa Proconsula- }\end{array}$ \\
\hline 7 & Antonino Pío & $\begin{array}{l}\text { C. Septimius } \\
\text { Severus }\end{array}$ & $\begin{array}{l}\text { Sodalis Hadrianalis, } \\
\text { XVvir s.f. }\end{array}$ & $\begin{array}{l}\text { Leptis Magna } \\
\text { Africa Proconsula- }\end{array}$ \\
\hline 8 & Antonino Pío & $\begin{array}{l}\text { C. Iulius Geminius } \\
\text { Capellianus }\end{array}$ & Sodalis Titius ${ }^{132}$ & $\begin{array}{l}\text { Cirta } \\
\text { Numidia }\end{array}$ \\
\hline 9 & $\begin{array}{l}\text { Antonino Pío o } \\
\text { Marco Aurelio }\end{array}$ & $\begin{array}{l}\text { M. Postumius } \\
\text { Festus }\end{array}$ & $\begin{array}{l}\text { Flamen (Ulpialis?) } \\
\text { VIIvir Epulonum }\end{array}$ & $\begin{array}{l}\text { Cirta } \\
\text { Numidia }\end{array}$ \\
\hline 10 & $\begin{array}{l}\text { Antonino Pío } \\
\text { Marco Aurelio }\end{array}$ & $\begin{array}{l}\text { L. Octavius } \\
\text { Cornelius } \\
P \text {. Salvius } \\
\text { Iulianus } \\
\text { Aemilianus }\end{array}$ & $\begin{array}{l}\text { Pontifex, Sodalis } \\
\text { Hadrianalis, } \\
\text { Sodalis } \\
\text { Antoninianus } \\
\text { (creada en el 161) }^{134}\end{array}$ & $\begin{array}{l}\text { Hadrumetum } \\
\text { Africa Proconsula- } \\
\text { ris }\end{array}$ \\
\hline 11 & Marco Aurelio & $\begin{array}{l}\text { Q. Antistius Ad- } \\
\text { ventus Postumius } \\
\text { Aquilinus }\end{array}$ & Fetialis $^{135}$ & $\begin{array}{l}\text { Thibilis } \\
\text { Numidia }\end{array}$ \\
\hline 12 & Marco Aurelio & $\begin{array}{l}\text { C. Arrius } \\
\text { Antoninus }\end{array}$ & $\begin{array}{l}\text { Frater Arvalis, } \\
\text { Augur, } \\
\text { Sodalis } \\
\text { Antoninianus }^{136}\end{array}$ & $\begin{array}{l}\text { Cirta } \\
\text { Numidia }\end{array}$ \\
\hline 13 & Marco Aurelio & $\begin{array}{l}\text { P. Iulius Geminius } \\
\text { Marcianus }\end{array}$ & Sodalis Titius ${ }^{137}$ & $\begin{array}{l}\text { Cirta } \\
\text { Numidia }\end{array}$ \\
\hline
\end{tabular}

130 Cooptado entre la prefectura del erario (153?-156?) y el consulado (158). CIL VI 1517=D 1080; RÜPKE, J., Op. Cit., p. 1282, no 3064.

131 Sería cooptado a lo largo de la pretura, entre el 155-158. AE 1917/1918, 60=ILAlg, I, 1283; SCHUMACHER, L., Die vier hohen römischen Priesterkollegien..., p. 686, n49; RÜPKE, J., Op. Cit., pp. $1275-6, \mathrm{n} \times 3035$.

132 Anterior a su gobierno de Pannonia Inferior y al consulado del 161-162. CIL III, 3419; RÜPKE, J., Op. Cit., p. 1068, no 2038.

${ }^{133}$ En sustitución del Flamen Ulpialis, P. Coelius Balbinus Vibullius Pius. RÜPKE, J., Op. Cit., p. 1234 , no 2826 explica que en función de la situación del flaminado en la inscripción (CIL VI 1416=D 2929) no debería tratarse de un cargo local, como así lo había propuesto SCHUMACHER, Leonhard, Prosopographische Untersuchungen zur Besetzung der vier hohen römischen Priesterkollegien im Zeitalter der Antonine und der Severer (96-235 n.Chr.), Mainz, 1973, p. 237.

${ }_{134}$ Entraría en los colegios sacerdotales ya como cónsul. CIL VIII, 24094=D 8973; RÜPKE, J., Op. Cit., p. $1179, \mathrm{n}^{\circ} 2559$.

135 Durante la pretura o tras su consulado. AE 1893, 88=D 8977 = ILAlg II, 4681; AE 1914, 281; RÜPKE, J., Op. Cit., p. 763, nº 638 .

${ }_{136}$ Arval tras la pretura (en torno al 164.); Augur hacia su consulado; Sodalis Antoninianus todavía bajo Marco Aurelio. CIL VIII, 7030=D 1119; SCHUMACHER, L., Die vier hohen römischen Priesterkollegien..., p. 680, no33; SCHEID, J., Le collège des frères arvales.. pp. 101-102, no 128; Ídem, Commentarii Fratrum Arvalium...p. 270, fragmento no 95a, línea 12; RÜPKE, J., Op. Cit., p. 780, no 717.

137 Cooptado en torno a su consulado, seguramente entre éste y el proconsulado de Asia 185-186. CIL VIII, 7050=D 1102; RÜPKE, J., Op. Cit., p. 1068, no 2037. 


\begin{tabular}{|c|c|c|c|c|}
\hline 14 & Marco Aurelio & $\begin{array}{l}\text { L. Antistius Burrus } \\
\text { Adventus }\end{array}$ & Salius Palatinus ${ }^{138}$ & $\begin{array}{l}\text { Thibilis } \\
\text { Numidia }\end{array}$ \\
\hline 15 & $\begin{array}{l}\text { Marco Aurelio- } \\
\text { Cómodo }\end{array}$ & $\begin{array}{l}\text { C. Vettius Sabinia- } \\
\text { nus Iulius Hospes }\end{array}$ & Sodalis Titius ${ }^{139}$ & $\begin{array}{l}\text { Thuburbo Maius } \\
\text { Africa Proconsularis }\end{array}$ \\
\hline 16 & Cómodo & P. Septimius Geta & Fetialis $^{140}$ & $\begin{array}{l}\text { Leptis Magna } \\
\text { Africa Proconsularis }\end{array}$ \\
\hline 17 & Cómodo & $\begin{array}{l}\text { Aemilius Fronti- } \\
\text { nianus }\end{array}$ & $\begin{array}{l}\text { Forma parte del } \\
\text { ordo de los sacer- } \\
\text { dotes domus Au- } \\
\text { gustae Palatinae }{ }^{141}\end{array}$ & $\begin{array}{l}\text { Oea } \\
\text { Africa Proconsularis }\end{array}$ \\
\hline 18 & Cómodo & $\begin{array}{l}\text { M. Asinius Rufi- } \\
\text { nus Valerius Ve- } \\
\text { rus Sabinianus }\end{array}$ & Fetialis $^{142}$ & $\begin{array}{l}\text { Acholla } \\
\text { Africa Proconsularis }\end{array}$ \\
\hline 19 & Cómodo & $\begin{array}{l}\text { C. Memmius Fi- } \\
\text { dus Iulius Albius }\end{array}$ & Sodalis Titius ${ }^{143}$ & $\begin{array}{l}\text { Bulla Regia } \\
\text { Africa Proconsularis }\end{array}$ \\
\hline 20 & Cómodo & $\begin{array}{l}\text { I]unius [-] [-- } \\
\text { ]cus Gar[gilius(?)] } \\
\text { [-]ntil[i]anus }\end{array}$ & $\begin{array}{l}\text { Sodalis Flavialis } \\
\text { Titialis }^{144}\end{array}$ & $\begin{array}{l}\text { Cirta? } \\
\text { Numidia }\end{array}$ \\
\hline 21 & $\begin{array}{l}\text { Cómodo o } \\
\text { Septimio Severo }\end{array}$ & $\begin{array}{l}\text { Q. Caecilius } \\
\text { Laetus }\end{array}$ & $\begin{array}{l}\text { Sodalis Augusta- } \\
\text { lis }{ }^{145}\end{array}$ & $\begin{array}{l}\text { Cirta } \\
\text { Numidia }\end{array}$ \\
\hline 22 & $\begin{array}{l}\text { Cómodo o } \\
\text { Septimio } \\
\text { Severo }\end{array}$ & $\begin{array}{l}\text { Sex. Caecilius } \\
\text { Aemilianus }\end{array}$ & VIlvir Epulonum ${ }^{146}$ & $\begin{array}{l}\text { Thuburbo Maius } \\
\text { Africa Proconsularis }\end{array}$ \\
\hline
\end{tabular}

138 Podría identificarse con el cónsul ordinario del 181 y cuñado de Cómdo, L. Antistius Burrus, seríaposiblemente patricio. CIL VI, 1979; RÜPKE, J., Op. Cit., p. 763-4, no 639.

139 ILAfr. 281

140 Seguramente durante o tras su pretura, en torno al 181 d.C. IRT 541=AE 1946, 131; RÜPKE, J., Op. Cit., p. 1275 , no 3033 .

141 CIL VI, 2010a, 29; RÜPKE, J., Op. Cit., p. 736, no 504.

142 Sería fetialis como pretor.AE 1954, 58 = AE 1955, 122 = AE 1956, 167

143 Sería sodalis posiblemente como pretor. CIL VIII, 12442; CIL VIII, 25527; RÜPKE, J., Op. Cit., p. 1149, no 2428.

144 Sería sodalis como pretor. CIL VI, 41127=AE 1995, 231=AE 2003, 00208 = AE 2005, +290; GREGORI, Gian Luca, «Un nuovo senatore dell'età di Commodo?», ZPE 106, (1995), pp. 269-279; RÜPKE, J., Op. Cit., p. 717-8, no393.

145 Recibiría este sacerdocio como pretor. CIL VIII, 8207; RÜPKE, J., Op. Cit., p. 830, no 976.

146 Cooptado antes de la cuestura como candidato. CIL VIII, 25367=AE 1899, 37=ILAfr 418; RÜPKE, J., Op. Cit., p. 829, no 969. 


\begin{tabular}{|c|c|c|c|c|}
\hline 23 & $\begin{array}{l}\text { Cómodo o } \\
\text { Septimio } \\
\text { Severo }\end{array}$ & $\begin{array}{l}\text { Q. Aiacius Mo- } \\
\text { destus Crescen- } \\
\text { tianus }\end{array}$ & $X V$ vir s.f..$^{147}$ & $\begin{array}{l}\text { Ignota } \\
\text { Africa Proconsularis }\end{array}$ \\
\hline 24 & $\begin{array}{l}\text { Cómodo- } \\
\text { Septimio } \\
\text { Severo }\end{array}$ & $\begin{array}{l}\text { L. Cornelius Sal- } \\
\text { vius Tuscus }\end{array}$ & $\begin{array}{l}\text { Salius Palatinus } \\
(181) \text { XVviri s.f. } \\
(204)^{148}\end{array}$ & $\begin{array}{l}\text { Hadrumetum } \\
\text { Africa Proconsularis }\end{array}$ \\
\hline 25 & $\begin{array}{l}\text { Cómodo- } \\
\text { Septimio } \\
\text { Severo }\end{array}$ & $\begin{array}{l}\text { L. Annius } \\
\text { Fabianus }\end{array}$ & $\begin{array}{l}\text { Salius Palatinus }{ }^{149} \\
\text { Flamen o cooptado } \\
\text { en alguno de los } \\
\text { colegios } \\
\text { mayores? }{ }^{150}\end{array}$ & $\begin{array}{l}\text { Caesarea } \\
\text { Mauretania Caesa- } \\
\text { rensis }\end{array}$ \\
\hline 26 & $\begin{array}{l}\text { Cómodo- } \\
\text { Septimio } \\
\text { Severo }\end{array}$ & $\begin{array}{l}\text { L. Pullaienus Gar- } \\
\text { gilius Antiquus }\end{array}$ & $X V$ vir s.f..$^{151}$ & $\begin{array}{l}\text { Thugga } \\
\text { Africa Proconsularis }\end{array}$ \\
\hline 27 & $\begin{array}{l}\text { Septimi0 } \\
\text { Severo }\end{array}$ & $\begin{array}{l}\text { Iulius Pompeius } \\
\text { Rusonianus }\end{array}$ & $\begin{array}{l}\text { Magister XVvir s.f. } \\
204^{152}\end{array}$ & $\begin{array}{l}\text { Leptis Magna } \\
\text { Africa Proconsularis }\end{array}$ \\
\hline 28 & $\begin{array}{l}\text { Septimio } \\
\text { Severo }\end{array}$ & $\begin{array}{l}\text { Ti. Claudius } \\
\text { Claudianus }\end{array}$ & $\begin{array}{l}\text { Sacerdos } \\
\text { Laurentium } \\
\text { Lavinatium, } \\
\text { VIlvir Epulonum }{ }^{153}\end{array}$ & $\begin{array}{l}\text { Cirta } \\
\text { Numidia }\end{array}$ \\
\hline 29 & $\begin{array}{l}\text { Septimio } \\
\text { Severo }\end{array}$ & $\begin{array}{l}\text { P.Porcius Optatus } \\
\text { Flamma }\end{array}$ & Sodalis Flavialis ${ }^{154}$ & $\begin{array}{l}\text { Cirta } \\
\text { Numidia }\end{array}$ \\
\hline
\end{tabular}

147 Documentado en los ludi seculares del 204 con rango de cónsul, pero bien pudo ser cooptado a finales de los años ochenta, siendo cuestor. CIL VI, 32327, 9, 12, 29; CIL VI, 32329, 8, 31; CIL VI, 32332,4; SCHUMACHER, L., Die vier hohen römischen Priesterkollegien..., p. 688, n66; RÜPKE, J., Op. Cit., p. 746 , n-549

148 Salius Palatinus desde el 181, y en el 204 figura ya entre los XVviri s.f. Es posiblemente patricio, y se desconoce la carrera. CIL VI, 32327, CIL VI 1979; RÜPKE, J., Op. Cit., p. 920-921, no 1367, SCHUMACHER, L., Die vier hohen römischen Priesterkollegien..., p. 688, n68.

149 Salius desde el 189. Posiblemente antes de su consulado (201) habría sido flamen o cooptado entre alguno de los colegios mayores; sería patricio CIL VI, 1980, 8.

150 Cfr. RÜPKE, J., Op. Cit., p. 757, no 604.

151 Figura entre los XVviri en los ludi seculares del 204 pero posiblemente fue cooptado en los últimos momentos de Cómodo. Adlectus inter patricios; CIL VI, 32329, 32; AE 1916, 118; SCHUMACHER, L., Die vier hohen römischen Priesterkollegien..., p. 688, no69; RÜPKE, J., Op. Cit., p. 1242, no 2862.

152 Cooptado tras su consulado, datado entre Cómodo y Severo. CIL VI, 32327.

153 Sacerdos Laurentium Lavinatium, como parte de su cursus ecuestre; luego Epulón, en el entorno de la pretura (194). CIL VIII, 7978=D 1147; SCHUMACHER, L., Die vier hohen römischen Priesterkollegien..., p. 696, no 57; SCHEID, J., GRANINO, M.G., Op. Cit., p. 27; RÜPKE, J., Op. Cit., p. 879, no 1177

154 Sería sodalis Flavialis como pretor. CIL VIII 7062= D 1143=ILAlg, II, 648 ; RÜPKE, J., Op. Cit., p. $1231, \mathrm{n}$ ㅇ 2812 . 


\begin{tabular}{|c|c|c|c|c|}
\hline 30 & $\begin{array}{l}\text { Septimio } \\
\text { Severo }\end{array}$ & $\begin{array}{l}\text { Ti. Claudius } \\
\text { Candidus }\end{array}$ & $X V$ vir s.f. ${ }^{155}$ & $\begin{array}{l}\text { Cirta } \\
\text { Numidia }\end{array}$ \\
\hline 31 & $\begin{array}{l}\text { Septimio } \\
\text { Severo }\end{array}$ & $\begin{array}{l}\text { Vettius } \\
\text { Sabinianus }{ }^{156}\end{array}$ & $\begin{array}{l}\text { Salius Palatinus } \\
199^{157}\end{array}$ & $\begin{array}{l}\text { Thuburbo Maius } \\
\text { Africa Proconsularis }\end{array}$ \\
\hline 32 & $\begin{array}{l}\text { Septimio } \\
\text { Severo }\end{array}$ & $\begin{array}{l}\text { L. Marius Maxi- } \\
\text { mus Perpetuus } \\
\text { Aurelianus }\end{array}$ & Fetialis $^{158}$ & $\begin{array}{l}\text { Ignota } \\
\text { Africa Proconsularis }\end{array}$ \\
\hline 33 & $\begin{array}{l}\text { Septimio } \\
\text { Severo }\end{array}$ & $\begin{array}{l}\text { C. Fulvius } \\
\text { Plautianus }\end{array}$ & $\begin{array}{l}\text { Pontifex }(202) \\
\text { XVvir s.f. }(203)^{159}\end{array}$ & $\begin{array}{l}\text { Leptis Magna } \\
\text { Africa Proconsularis }\end{array}$ \\
\hline 34 & $\begin{array}{l}\text { Septimio } \\
\text { Severo }\end{array}$ & $\begin{array}{l}\text { Fulvius Fuscus } \\
\text { Granianus }\end{array}$ & $X V$ vir s.f. $204^{160}$ & $\begin{array}{l}\text { Leptis Magna } \\
\text { Africa Proconsularis }\end{array}$ \\
\hline 35 & $\begin{array}{l}\text { Septimio } \\
\text { Severo }\end{array}$ & $\begin{array}{l}\text { C. Iunius Fausti- } \\
\text { nus Postumianus }\end{array}$ & $\begin{array}{l}\text { Sodalis Flavialis } \\
\text { Titialis }^{161}\end{array}$ & $\begin{array}{l}\text { Tituli } \\
\text { Africa Proconsularis }\end{array}$ \\
\hline 36 & Caracalla & $\begin{array}{l}\text { Sex. Furnius } \\
\text { Sulpicianus }\end{array}$ & $\begin{array}{l}\text { Magister de los } \\
\text { Sodales Augus- } \\
\text { tales Claudiales } \\
(213 \text { d.C. })^{162}\end{array}$ & $\begin{array}{l}\text { Ignota (Carthago?) } \\
\text { Africa Proconsularis }\end{array}$ \\
\hline 37 & Caracalla & $\begin{array}{l}\text { L. Insteius } \\
\text { Tertullus }{ }^{163}\end{array}$ & $\begin{array}{l}\text { Magister de los } \\
\text { Sodales Augus- } \\
\text { tales Claudiales en } \\
\text { el } 214{ }^{164}\end{array}$ & $\begin{array}{l}\text { Thuburbo Maius } \\
\text { Africa Proconsularis }\end{array}$ \\
\hline
\end{tabular}

155 Seguramente después de su victoria frente a Albino, siendo ya cónsul. CIL II, 4114=D 1140; RÜPKE, J., Op. Cit., p. 879, nำ1174.

156 Identificado con el Salio, ([--]ius Sabinianus (CIL VI, 1982,4).

157 CIL VI, 1982, 4

158 Sería fetialis en torno a su consulado. CIL VI, 1450; CIL X, 6567 y 6764; AE 1955, 188; RÜPKE, J., Op. Cit., p. 1141, no 2393.

159 Cooptado entre los ornamenta consularia (197-202) y su segundo consulado (203). Sería elevado al patriciado CIL VI, 1074=D 456; CIL VI, 32329,5; SCHUMACHER, L., Die vier hohen römischen Priesterkollegien..., p. 675, no 97, 689, nำ6; RÜPKE, J., Op. Cit., p. 1008, no 1773

160 Documentado posiblemente como cuestor. CIL VI, 32327, 11, 13; CIL VI, 32328,1; CIL VI, 32329, 32; CIL VI, 32332,1; SCHUMACHER, L., Die vier hohen römischen Priesterkollegien..., p. 689, $\mathrm{n} \div 84$; RÜPKE, J., Op. Cit., p. 1006, nำ 1764

161 Sería sodalis posiblemente como cónsul. CIL VIII, 597, RÜPKE, J., Op. Cit., p. 1081, no 2113.

162 CIL VI 1987,6, RÜPKE, J., Op. Cit., p. 1012, no 1793.

163 Su origo no es segura, pero podría ser originario de África y estar relacionado con el homónimo, Insteius Tertullus, clarissimus vir (CIL VIII 876) que elevaría una inscripción funeraria a Insteia Diogenia, femina merens cerca de Thuburbo Maius. Aunque también podrí relacionarse con estar L. Insteius L.f.Horatia Flaccianus, senador de Praeneste y Sodalis Hadrianalis en época de los severos.

${ }_{164}$ CIL VI 1987, 11=14, 2391, 11=Inscr. It. 13, 1, 313; RÜPKE, J., Op. Cit., p. 1045, no 1942. 
La participación de los senadores de origen africano...

\begin{tabular}{|c|c|c|c|c|}
\hline 38 & Heliogábalo & $\begin{array}{l}\text { Q. Aradius Rufi- } \\
\text { nus Optatus } \\
\text { Aelianus }\end{array}$ & $\begin{array}{l}\text { Sodalis Augustalis } \\
\text { (Claudialis) }^{165}\end{array}$ & $\begin{array}{l}\text { Bulla Regia } \\
\text { Africa Proconsularis }\end{array}$ \\
\hline 39 & $\begin{array}{l}\text { Alejandro } \\
\text { Severo }\end{array}$ & $\begin{array}{l}\text { A. Terentius } \\
\text { Pudens }{ }^{166}\end{array}$ & $\begin{array}{l}\text { Sodalis Augustalis } \\
\text { (Claudialis) } 229^{167}\end{array}$ & $\begin{array}{l}\text { Carthago } \\
\text { Africa Proconsularis }\end{array}$ \\
\hline 40 & $\begin{array}{l}\text { Alejandro } \\
\text { Severo }\end{array}$ & $\begin{array}{l}\text { C. Annius Anulli- } \\
\text { nus Geminus Per- } \\
\text { cennianus }\end{array}$ & $\begin{array}{l}\text { Frater Arvalis } \\
230^{168}\end{array}$ & $\begin{array}{l}\text { Theveste } \\
\text { Africa Proconsularis }\end{array}$ \\
\hline 41 & $\begin{array}{l}\text { Alejandro } \\
\text { Severo }\end{array}$ & $\begin{array}{l}\text { C. Arrius } \\
\text { Calpurnius Fronti- } \\
\text { nus Honoratus }\end{array}$ & Augur $r^{169}$ & $\begin{array}{l}\text { Avioccala } \\
\text { Africa Proconsularis }\end{array}$ \\
\hline 42 & $\begin{array}{l}\text { Severos } \\
\text { Maximino }\end{array}$ & $\begin{array}{l}{[- \text { - }] \text { undinus= }} \\
P . \text { Aelius } \\
\text { Sec?]undinus? }\end{array}$ & $\begin{array}{l}\text { Frater Arvalis }{ }^{170} \\
\text { VIIvir Epulonum }^{171}\end{array}$ & $\begin{array}{l}\text { Thugga } \\
\text { Africa Proconsularis }\end{array}$ \\
\hline 43 & s.IIl d.C. & $\begin{array}{l}\text { L. Pomponius } \\
\text { Dexter Celerinus }\end{array}$ & $\begin{array}{l}\text { Sodalis Aurelianus } \\
\text { Antoninianus }^{172}\end{array}$ & $\begin{array}{l}\text { Vaga } \\
\text { Africa Proconsularis }\end{array}$ \\
\hline 44 & $\begin{array}{l}\text { Segundo cuar- } \\
\text { to s.III d.C. }\end{array}$ & $\begin{array}{l}\text { M. Aurelius Co- } \\
\text { minius Cassianus }\end{array}$ & Augur $r^{173}$ & $\begin{array}{l}\text { Cirta } \\
\text { Numidia }\end{array}$ \\
\hline 45 & $\begin{array}{l}\text { Primera mitad } \\
\text { s.III d.C. }\end{array}$ & $\begin{array}{l}\text { Anonymus? } \\
\text { ILAfr. } 324\end{array}$ & Sacer $[\text { doti.... }]^{174}$ & $\begin{array}{l}\text { Vina } \\
\text { Africa Proconsularis }\end{array}$ \\
\hline
\end{tabular}

165 Cooptado antes de ser pretor. CIL VI 1984,2,18=D 5025; AE 1971, 490; RÜPKE, J., Op. Cit., p. 778 , no 706 .

166 Hijo de A.(Olus) Terentius Pudens Uttedianus, gobernador de Raetia bajo Severo. También ha sido relacionado con el patricio $A$. Terentius Priscus, consular, XVvir sacris faciundis y patricio (PANCIERA, Silvio, «Domus a Roma. Altri contributi alla loro inventariazione», en ANGELI BERTINELLI, Maria Gabriella, DONATI, Angela, (eds.) Usi e abusi epigrafici: atti del Colloquio Internazionale di Epigrafia Latina (Genova 20-22 settembre 2001), Roma, G. Bretschneider, 2003, p. 366.

167 CIL VI, 1984, 1, 43, 47=D 5025; RÜPKE, J., Op. Cit., p. 1317, no3233.

168 Cooptado después de su consulado. SCHEID, J., Le collège des frères arvales.. № 157; RÜP. KE, J., Op. Cit., p. 756-7, no 601.

169 Patricio, augur entre la pretura y el consulado. CIL III, 6810, 12=D 7198; AE 1914, 130; RÜPKE, J., Op. Cit., p. 780, no 718 .

170 Figura como magister del colegio de los Arvales en el 219, y de nuevo en el 237.

171 CIL VIII, 26577a-C = ILTun 1420 = Dougga 66a; SCHUMACHER, L., Die vier hohen römischen Priesterkollegien..., p. 696, no 66; SCHEID, J., Le collège des frères arvales.. no 150; RÜPKE, J., Op. Cit., p. $732, \mathrm{n}^{\circ} 482$.

172 Cónsul en año incierto, se desconoce en qué momento fue cooptado. CIL VIII, 1222 ; RÜPKE, J., Op. Cit., p. 1223, no 2776.

173 Figuraría entre los augures antes de la cuestura. CIL VIII 7033=ILAlg II, 617.

174 ILAfr. 324 = D 8980 = AE 1909, 22; BIRLEY, Anthony Richard, The Roman Government of Britain, Oxford, Oxford University Press, 2005, pp. 295-296 reconstruye la inscripción, entre la segunda y la tercera línea, de esta forma: sace[rdoti fetiali?/sodali Antoninia]no. Sin embargo no deja de ser una hipótesis dado el estado de la inscripción. 


\begin{tabular}{|l|l|l|l|l|}
\hline 46 & $\begin{array}{l}\text { Primera mitad } \\
\text { s.III } \\
\text { Gordiano III }\end{array}$ & $\begin{array}{l}\text { C. Arrius } \\
\text { Calpurnius } \\
\text { Longinus }\end{array}$ & Augur & $\begin{array}{l}\text { Avioccala } \\
\text { Africa Proconsularis }\end{array}$ \\
\hline 47 & Mediados s.III & $\begin{array}{l}\text { Q. Octavius Volu- } \\
\text { sius Thuscenius }\end{array}$ & Salius Collinus & $\begin{array}{l}\text { Utica } \\
\text { Africa Proconsularis }\end{array}$ \\
\hline 48 & $\begin{array}{l}\text { Mediados s.III } \\
\text { d.C. }\end{array}$ & $\begin{array}{l}\text { C. Memmius Cae- } \\
\text { cilianus Placidus }\end{array}$ & Augur & $\begin{array}{l}\text { Gigthis } \\
\text { Africa Proconsularis }\end{array}$ \\
\hline 49 & $\begin{array}{l}\text { Cronología in- } \\
\text { cierta, media- } \\
\text { dos s.Illd.C.? }\end{array}$ & $\begin{array}{l}\text { L. Cassius Mani- } \\
\text { lianus }\end{array}$ & Curio minor & $\begin{array}{l}\text { Furnos Maius } \\
\text { Africa Proconsularis }\end{array}$ \\
\hline
\end{tabular}

175 Patricio y augur como su padre, cooptado al igual que él entre pretura y consulado. CIL VIII, 23831; RÜPKE, J., Op. Cit., p. 780-1, oㅜ 719.

176 CIL VIII, = CIL VIII, 9260 = CIL VIII, 14312 = AE 2004, +69; RÜPKE, J., Op. Cit., p. 1179-80, oㅡ 2564.

177 Rüpke lo propone como patricio, pero no es obligatorio que lo fuera. En principio por los orígenes de su familia no se intuiría una pertenencia al patriciado. CIL VI, 31737; CIL XI, 5740; RÜPKE, J., Op. Cit., p. 1149 , no 2427.

${ }_{178}$ Es un sacerdocio destinado normalmente a caballeros, pero también hay senadores así documentados. AE 1990, 438; SCHEID, J., GRANINO, M.G., Op. Cit., p. 11; RÜPKE, J., Op. Cit., p. 863, no 1107 